\title{
Localization and Expression of Group I Metabotropic Glutamate Receptors in the Mouse Striatum, Globus Pallidus, and Subthalamic Nucleus: Regulatory Effects of MPTP Treatment and Constitutive Homer Deletion
}

\author{
Masaaki Kuwajima, ${ }^{1,2}$ Marlin H. Dehoff, ${ }^{4}$ Teiichi Furuichi, ${ }^{5}$ Paul F. Worley, ${ }^{4}$ Randy A. Hall, ${ }^{2}$ and Yoland Smith ${ }^{1,3}$ \\ ${ }^{1}$ Yerkes National Primate Research Center and Departments of ${ }^{2}$ Pharmacology and ${ }^{3}$ Neurology, Emory University School of Medicine, Atlanta, Georgia \\ 30322, ${ }^{4}$ Department of Neuroscience, Johns Hopkins University School of Medicine, Baltimore, Maryland 21205, and ${ }^{5}$ Laboratory for Molecular \\ Neurogenesis, RIKEN Brain Science Institute, Wako, Saitama 351-0198, Japan
}

\begin{abstract}
Group I metabotropic glutamate receptors (mGluRs), mGluR1 and mGluR5, regulate activity in the globus pallidus (GP) and subthalamic nucleus (STN). To test whether the localization of group I mGluRs is altered in parkinsonism, we used immunoelectron microscopy to analyze the subcellular and subsynaptic distribution of mGluR1a and mGluR5 in GP and STN of 1-methyl-4-phenyl-1,2,3,6tetrahydropyridine (MPTP)-treated mice. Homer1 and Homer2 knock-out mice were used to assess the role of Homer in MPTP-induced redistribution of group I mGluRs. We also examined the effects of MPTP on the expression levels of group I mGluRs and Homer proteins in GP and striatum. MPTP treatment significantly reduced the expression levels of Hla and mGluRla in striatum but not in GP. Although light microscopy did not reveal noticeable effects of MPTP treatment on the distribution of group I mGluRs and Homer proteins in GP and STN, specific changes in the ultrastructural localization of mGluRla were found in MPTP-treated normal and Homer knock-out mice. An increase in the expression of presynaptic axonal and terminal mGluR1a labeling and an increased level of mGluR1a immunoreactivity in the postsynaptic specialization of putative GABAergic synapses were among the most significant effects induced by dopamine depletion. However, neither of these changes was found for mGluR5, which, in contrast, displayed complex regulatory alterations in its subsynaptic distribution in response to Homer deletion and MPTP lesion. Thus, nigrostriatal dopaminergic lesion and Homer deletion lead to changes in the trafficking of group I mGluRs in vivo that are specific to receptor subtypes and brain areas.
\end{abstract}

Key words: ultrastructure; immunogold; basal ganglia; Parkinson's disease; MPTP; plasticity

\section{Introduction}

The major pathophysiological features of Parkinson's disease include an increased and/or burst firing activity of neurons in the subthalamic nucleus (STN) and increased synchronization of activity within the STN-globus pallidus (GP) network, resulting in the disruption of information flow through the basal ganglia (Wichmann and DeLong, 2003). Understanding factors that regulate neuronal excitability in GP and STN would be an important step forward in elucidating the role of these nuclei in normal motor control and the pathophysiological changes that underlie Parkinson's disease.

Group I metabotropic glutamate receptors (mGluRs) are $\mathrm{G}_{\mathrm{q}^{-}}$ coupled heptahelical receptors that are widely expressed postsynaptically in basal ganglia nuclei, including the GP (Hanson and

Received Sept. 1, 2006; revised May 3, 2007; accepted May 3, 2007.

This work was supported by grants from the National Institutes of Health (NIH) to Y.S., R.A.H., and P.F.W., the Yerkes Center NIH base grant (RR00165), and the W. M. Keck Foundation (a Distinguished Young Scholar in Medical Research award to R.A.H.). We thank Jean-François Paré, Susan Maxson, Amanda M. Castleberry, and Heide Oller for their technical assistance.

Correspondence should be addressed to Dr. Yoland Smith, Yerkes National Primate Research Center, Emory University, 954 Gatewood Road NE, Atlanta, GA 30329. E-mail:ysmit01@emory.edu.

D0I:10.1523/JNEUROSCI.3819-06.2007

Copyright $\odot 2007$ Society for Neuroscience $\quad$ 0270-6474/07/276249-12\$15.00/0
Smith, 1999) and STN (Kuwajima et al., 2004). Although coupled to the same second messenger cascade, mGluR1 and mGluR5 can serve different physiologic functions even when they are coexpressed in the same basal ganglia neurons (Valenti et al., 2002). Furthermore, the physiologic responses of group I mGluRs activation in the basal ganglia display a high degree of plasticity in response to haloperidol- or reserpine-induced decrease in dopaminergic transmission (Marino et al., 2002). Although the mechanisms underlying these functional changes remain poorly understood, one explanation for such alterations in the physiologic actions would be that the subsynaptic distribution of group I mGluRs changes after dopaminergic antagonism, which may reflect differential mechanisms for their intracellular trafficking.

The trafficking of mGluR1a and mGluR5 is regulated by a family of scaffolding proteins called Homer, which are encoded by three genes (Homer 1-3). Most Homer proteins (i.e., H1b/c, 2, and 3; referred to as "long Homer") are constitutively expressed throughout the CNS, except for Homerla (H1a), which is inducible by various forms of neuronal stimulation, such as enhancement of dopaminergic activity (Xiao et al., 2000; de Bartolomeis and Iasevoli, 2003). Previous studies in cultured cells indicate that Homer proteins regulate the trafficking of group I mGluRs to the plasma membrane (Roche et al., 1999) and to different 
Table 1. Summary of primary antibodies used for immunocytochemistry and Western blot in this study

\begin{tabular}{|c|c|c|c|c|c|}
\hline Antibody & Type & Epitope & Dilution & Source & Specificity tests \\
\hline mGluR1a & Rabbit polyclonal; affinity-purified & $\begin{array}{l}\text { C-terminal residues } 1180-1199 \text { of rat } \\
\text { mGluR1a }\end{array}$ & $\begin{array}{l}0.5 \mu \mathrm{g} / \mathrm{ml}(\mathrm{ICC}) \\
0.04 \mu \mathrm{g} / \mathrm{ml} \\
\text { (WB) }\end{array}$ & Millipore & $\begin{array}{c}\text { Testa et al. (1998) (PA-IHC); Ferraguti } \\
\text { et al. (1998) (TC/KO-WB); Marino } \\
\text { et al. (2001) (TC-WB); Kuwajima } \\
\text { et al. (2004) (TC-WB, KO-IHC) }\end{array}$ \\
\hline mGluR5 & Rabbit polyclonal; affinity-purified & $\begin{array}{l}\text { C-terminal residues } 1152-1171 \text { of rat } \\
\text { mGluR5 }\end{array}$ & $\begin{array}{c}0.86 \mu \mathrm{g} / \mathrm{ml}(\mathrm{ICC}) \\
0.17 \mu \mathrm{g} / \mathrm{ml} \\
(\mathrm{WB})\end{array}$ & Millipore & $\begin{array}{l}\text { Marino et al. (2001) (TC-WB); Kuwa- } \\
\text { jima et al. (2004) (TC-WB, KO-IHC) }\end{array}$ \\
\hline Homer1b/c & $\begin{array}{l}\text { Rabbit polyclonal; preabsorbed with } \\
\mathrm{H} 2 \text { and } \mathrm{H} 3 \text {, then affinity-purified }\end{array}$ & Residues $152-366$ of mouse $\mathrm{H} 1 \mathrm{c}$ & $1: 5,000(\mathrm{ICC})$ & Shiraishi et al. (2003) & $\begin{array}{l}\text { Shiraichi et al. (2003) (TC-WB); also } \\
\text { see Fig. } 3 \text { for KO-IHC }\end{array}$ \\
\hline Homer2 & $\begin{array}{l}\text { Rabbit polyclonal; preabsorbed with } \\
\mathrm{H} 1 \text { and } \mathrm{H} 3 \text {, then affinity-purified }\end{array}$ & Residues $142-343$ of mouse $\mathrm{H} 2 \mathrm{a}$ & $1: 5,000(\mathrm{ICC})$ & Shiraishi et al. (2003) & $\begin{array}{l}\text { Shiraichi et al. (2003) (TC-WB); also } \\
\text { see Fig. } 3 \text { for KO-IHC }\end{array}$ \\
\hline Homer3 & $\begin{array}{l}\text { Rabbit polyclonal; preabsorbed with } \\
\mathrm{H} 1 \text { and } \mathrm{H} 2 \text {, then affinity-purified }\end{array}$ & Residues $131-358$ of mouse $\mathrm{H} 3$ & $1: 5,000(\mathrm{ICC})$ & Shiraishi et al. (2003) & Shiraichi et al. (2003) (TC-WB) \\
\hline Homer & Rabbit polyclonal & Residues 13-354 of human Homer1b & $1: 100$ (WB) & Santa Cruz Biotechnology & Santa Cruz Biotechnology (WB) \\
\hline DAT & Rat monoclonal & $\begin{array}{l}\text { N terminus of human DAT fused to } \\
\text { Glutathione S-transferase }\end{array}$ & $1: 500$ (ICC) & Millipore & Miller et al. (1997) (TC-WB) \\
\hline $\mathrm{TH}$ & Rabbit polyclonal; affinity-purified & $\begin{array}{l}\text { Rat TH from pheochromocytoma dena- } \\
\text { tured by SDS }\end{array}$ & $1: 5,000(\mathrm{WB})$ & Millipore & Millipore (WB) \\
\hline Actin & Goat polyclonal; affinity-purified & C terminus of human actin & $1: 500$ (WB) & Santa Cruz Biotechnology & Santa Cruz Biotechnology (WB) \\
\hline
\end{tabular}

ICC, Immunocytochemistry; IHC, immunohistochemistry; KO, knock-out mouse tissue; PA, preadsorption; TC, transfected cells; WB, Western immunoblots.

neuronal compartments (Ango et al., 2000), but the importance of Homer-mGluR interactions in vivo remain unknown.

We hypothesized that, in the 1-methyl-4-phenyl-1,2,3,6tetrahydropyridine (MPTP)-treated mouse model of Parkinson's disease, reduced dopamine content in the basal ganglia would alter the expression of Homer proteins, which, in turn, could affect the localization of group I mGluRs in GP and STN. Thus, using immunoelectron microscopic methods, we analyzed the subcellular and subsynaptic localization of mGluRla and mGluR5 in the GP and STN of wild-type mice treated with MPTP. To identify which Homer isoform is involved in MPTPinduced redistribution of group I mGluRs in these brain areas, mice lacking $\mathrm{H} 1$ or $\mathrm{H} 2$ were also treated with MPTP. In addition, the effects of MPTP treatment on the total expression levels of group I mGluRs and Homer proteins in GP and striatum (STR) were analyzed by Western immunoblot. Some of these data have been published in abstract form (Kuwajima et al., 2005).

\section{Materials and Methods}

Animals and MPTP treatment. All procedures were approved by the animal care and use committees of Emory University and The Johns Hopkins University and conformed to the National Institutes of Health guidelines. Generation of Homer1 [CMV-Cre $(\mathrm{BALB} / \mathrm{cJ}) \times$ Flpe $(\mathrm{C} 57 \mathrm{BL} / 6 \times 129 \mathrm{sv}) \times \mathrm{C} 57 \mathrm{BL} / 6$ (Yuan et al., 2003)] and Homer2 [129sv $\times$ C57BL/6 (Shin et al., 2003)] knock-out mice has been described previously. Mice were randomly assigned to receive injections of either MPTP (Sigma, St. Louis, MO) or saline (SAL). For immunocytochemistry, the following animals were used ( $n=\mathrm{SAL} / \mathrm{MPTP})$ : Homer 1 knockout (H1ko; $n=4 / 6)$ and their littermate wild-type mice (H1wt; $n=5 / 3)$; Homer2 knock-out (H2ko; $n=4 / 5)$ and their littermate wild-type mice (H2wt; $n=5 / 6$ ). Because of the limited number of animals that were available, both males and females were used for each genotype group (average male-to-female ratio, 0.6). Because there was no noticeable difference in the localization of group I mGluRs between males and females, data gathered from both sexes were pooled. Animals in the MPTP group received four weekly intraperitoneal injections of $25 \mathrm{mg} / \mathrm{kg}$ MPTP dissolved in $0.9 \%$ saline (i.e., cumulative dose of $100 \mathrm{mg} / \mathrm{kg}$ ). This dose of MPTP was chosen based on a previous study (Bezard et al., 1997). The animals in the SAL group received four weekly intraperitoneal injections of $0.9 \%$ saline $(10 \mathrm{ml} / \mathrm{kg})$. Seven days after the last injection, animals were deeply anesthetized with an overdose of pentobarbital (100 mg/kg, i.p.), and transcardially perfused with oxygenated Ringer's solution, followed by a fixative solution containing $4.0 \%$ paraformaldehyde and $0.1-0.2 \%$ glutaraldehyde in phosphate buffer (PB; $0.1 \mathrm{M} ; \mathrm{pH}$ 7.4). The brain was then removed from the skull and postfixed in the same fixative for at least $12 \mathrm{~h}$ at $4^{\circ} \mathrm{C}$ before being washed in PBS $(0.01 \mathrm{M} ; \mathrm{pH} 7.4)$ and cut in 50 - to $60-\mu \mathrm{m}$-thick coronal sections with a vibrating microtome.

For Western immunoblot, the following mice $(n=\mathrm{SAL} / \mathrm{MPTP})$ were used: H1wt $(n=9 / 5)$, H2wt $(n=4 / 3)$, and normal C57BL/6 mice $(n=$ 4/6; Charles River Laboratories, Wilmington, MA). Seven days after the last MPTP or SAL injection, they were rapidly decapitated, the brain was removed from the skull, and the striatum and GP were dissected out. Again, both males and females were used for each strain (average maleto-female ratio, 0.8 ), and all strain groups were pooled together, because our preliminary analysis did not show any significant effect of strain background on group I mGluRs and Homer protein expression levels.

Primary antibodies. To localize group I mGluRs, we used rabbit antimGluR1a (Millipore, Billerica, MA) and rabbit anti-mGluR5 (Millipore) polyclonal antibodies. The mGluRla and mGluR5 antibodies have previously been tested for specificity with Western immunoblot using samples from transfected cells (Marino et al., 2001; Kuwajima et al., 2004) and knock-out mice brain tissue (Ferraguti et al., 1998), as well as immunohistochemistry performed with antibody preabsorption (Testa et al., 1998) or on knock-out brain tissues (Kuwajima et al., 2004). For the immunoperoxidase localization of Homer proteins, rabbit polyclonal antibodies against H1b/c (1:5000), H2 (1:5000), and H3 (1:5000) were used (Shiraishi et al., 2003, 2004). Each antibody was preabsorbed with two other Homer proteins, followed by affinity purification with the corresponding antigen. The specificity of these antibodies was confirmed with Western immunoblot using samples from cell lines transfected with Homer cDNAs (Shiraishi et al., 2003).

The extent of the MPTP-induced nigrostriatal lesion was assessed by immunocytochemistry with a monoclonal rat antibody against dopamine transporter (DAT; 1:500; Millipore) and by Western immunoblot with a polyclonal rabbit antibody against tyrosine hydroxylase (TH; 1:5000; Millipore). To assess the expression levels of Homer proteins in GP and striatum, we used a polyclonal rabbit antibody against Homer (1:100; Santa Cruz Biotechnology, Santa Cruz, CA), which recognizes all Homer isoforms ( $\mathrm{Hla}$ at $\sim 27 \mathrm{kDa}$ and long Homers at $\sim 45 \mathrm{kDa}$ ). Actin was used as loading control and labeled with a polyclonal goat anti-actin antibody (1:500; Santa Cruz Biotechnology). Details of antibodies used in this study are summarized in Table 1.

Western immunoblot. Brain tissue was sonicated in ice-cold buffer solution containing $10 \mathrm{~mm}$ HEPES, $50 \mathrm{~mm} \mathrm{NaCl}, 0.1 \mathrm{~mm}$ EDTA, $1 \mathrm{~mm}$ benzamidine, $1.0 \%$ Triton X-100, $0.1 \%$ SDS, and protease inhibitor mix- 
ture (Complete; 1 tablet per $50 \mathrm{ml}$; Roche Applied Science, Mannheim, Germany). The lysates (30 $\mu \mathrm{g}$ of protein) were then eluted with $6 \times$ SDS-PAGE sample buffer. The samples from brain tissue were resolved by SDS-PAGE and subjected to Western blot analysis with appropriate antibodies. We used the enhanced chemiluminescence detection system (Pierce, Rockford, IL) with horseradish peroxidase-conjugated donkey anti-rabbit (1:4000; GE Healthcare, Little Chalfont, UK) and chicken anti-goat (1:5000; Millipore) secondary antibodies to detect immunoreactive bands, which were then analyzed with ImageJ software. MPTPtreated mice that did not show $>80 \%$ loss of $\mathrm{TH}$ protein expression in the striatum were excluded from the analysis. Protein expression levels were normalized to the saline-treated subjects, and the effects of MPTP treatment were analyzed by $t$ test.

Light microscopic localization of group I mGluRs, Homers, and DAT by immunoperoxidase method. Tissue sections were treated with $1.0 \%$ $\mathrm{NaBH}_{4}$ in PBS for 20 min at room temperature (RT), followed by PBS rinses. The sections were then incubated for $1 \mathrm{~h}$ at RT in PBS containing $5 \%$ nonfat dry milk and $0.3 \%$ Triton X-100, followed by the primary antibody solution containing $1.0 \%$ milk and $0.3 \%$ Triton X-100 in PBS for $24 \mathrm{~h}$ at RT. After PBS rinses, the sections were incubated for $90 \mathrm{~min}$ in biotinylated goat anti-rabbit IgG (1:200; Vector Laboratories, Orton Southgate, UK) diluted in the antibody diluent solution, followed by avidin-biotin-peroxidase complex (Vector Laboratories). The sections were then washed in PBS and Tris buffer ( $50 \mathrm{~mm}$; $\mathrm{pH} 7.6)$ and transferred to a solution containing $0.025 \% 3,3^{\prime}$-diaminobenzidine tetrahydrochloride (DAB; Sigma), $10 \mathrm{~mm}$ imidazole, and $0.005 \%$ hydrogen peroxide in Tris buffer for $10 \mathrm{~min}$. After PBS washes, the sections were mounted on gelatin-coated slides and dehydrated, and a coverslip was applied with Permount. They were examined with a Leica DMRB microscope (Leica Microsystems, Bannockburn, IL), and images were acquired with a CCD camera (Leica DC500) controlled by Leica IM50 software (version 1.20). To avoid interindividual variability in Homer staining intensity caused by inherent differences between animals and immunohistochemical reactions, we made sure to incubate GP and STN tissue from the same animals with the different Homer antibodies, and each of these reactions were done at the same time using the same solutions, except for primary antibodies.

Immunoperoxidase localization of group I $m G l u R s$ at the electron microscopic level. After $\mathrm{NaBH}_{4}$ treatment, the sections were placed in a cryoprotectant solution for $20 \mathrm{~min}$, followed by freeze thawing as described previously (Hubert et al., 2001). The sections then underwent processing for the immunoperoxidase localization of group I mGluRs in a manner identical to that for light microscopy, except that the incubation with the primary antibodies was performed at $4^{\circ} \mathrm{C}$ for $48 \mathrm{~h}$, and Triton X-100 was omitted from all incubation solutions. After immunostaining, the sections were transferred to $\mathrm{PB}$ for $10 \mathrm{~min}$ and treated with $1.0 \% \mathrm{OsO}_{4}$ in $\mathrm{PB}$ for $20 \mathrm{~min}$. They were then rinsed with $\mathrm{PB}$ and dehydrated in an ascending gradient of ethanol. Uranyl acetate $(1.0 \%)$ was added to the $70 \%$ alcohol to enhance contrast. The sections were then treated with propylene oxide before being embedded in epoxy resin (Durcupan ACM; Fluka, Buchs, Switzerland) for $24 \mathrm{~h}$, mounted on microscope slides, and placed in the oven at $60^{\circ} \mathrm{C}$ for $48 \mathrm{~h}$. Samples of GP and STN were then cut out from the slides, glued on the top of resin blocks with cyanoacrylate glue, and cut into 60-nm-thick ultrathin sections with an ultramicrotome (Leica Ultracut T2). The ultrathin sections were serially collected on single-slot Pioloform-coated copper grids, stained with lead citrate for $5 \mathrm{~min}$, and examined with a Zeiss (Thornwood, NY) EM-10C electron microscope. The micrographs were acquired with a CCD camera (DualView 300W; Gatan, Pleasanton, CA) controlled by DigitalMicrograph software (version 3.6.5, 3.8.1, or 3.9.1; Gatan). Some digitally acquired micrographs were adjusted only for brightness and contrast, while maintaining the image resolution constant, with either DigitalMicrograph or Photoshop software (version 7.0; Adobe Systems, San Jose, CA) to optimize the quality of the images for analysis.

Preembedding immunogold labeling of group I mGluRs. After freeze thawing, sections processed for preembedding immunogold staining were incubated for $1 \mathrm{~h}$ at RT in a solution containing $5 \%$ milk in PBSBSA $(0.005 \%$ BSA, $0.05 \%$ Tween 20 , and $0.001 \%$ gelatin in PBS). The sections were then incubated with PBS-BSA containing $1 \%$ milk and the primary antibodies for $48 \mathrm{~h}$ at $4^{\circ} \mathrm{C}$. After rinses in PBS-BSA, the sections were incubated for $2 \mathrm{~h}$ at RT with goat anti-rabbit IgGs conjugated with $1.4 \mathrm{~nm}$ gold particles (1:100; Nanoprobes, Yaphank, NY) in PBS-BSA with $1 \%$ milk. The sections were then fixed in $1 \%$ glutaraldehyde in PBS for $10 \mathrm{~min}$ at $4^{\circ} \mathrm{C}$ and rinsed with $\mathrm{PB}$, followed by silver intensification of the gold particles with the HQ silver kit (Nanoprobes) for 5-10 min. They were then rinsed with $\mathrm{PB}$ and treated with $0.5 \% \mathrm{OsO}_{4}$ in $\mathrm{PB}$ for 10 $\min$. The rest of the procedure was the same as that described above for the immunoperoxidase material.

Control incubations. Tissue sections were also incubated in the absence of primary antibodies to control for immunostaining generated by nonspecific binding of the secondary antibodies. In addition, to control for nonspecific staining generated by endogenous biotin (McKay et al., 2004), peroxidase (Matsumoto, 1985), and Zn (Veznedaroglu and Milner, 1992), tissue sections were incubated with (1) avidin-biotin-peroxidase complex and DAB, (2) DAB only, or (3) HQ silver only, respectively. These control incubations were performed in parallel with normal incubations and resulted in the total absence of immunoreactivity (ir) at both light microscopic (LM) and electron microscopic (EM) levels.

Analysis of immunostained material. Light micrographs of the DATstained striatal sections were acquired as described above, and the intensity of the peroxidase labeling was measured in the dorsal striatum at the level of anterior commissure decussation $[\sim 0.14 \mathrm{~mm}$ anterior to the bregma, according to Paxinos and Franklin (2001)] with the ImageJ software (version 1.34s; National Institutes of Health, Bethesda, MD; http://rsb.info.nih.gov/ij/) to assess the extent of MPTP-induced loss of dopaminergic fibers in the striatum. MPTP-treated mice that did not show $>80 \%$ loss of DAT labeling (compared with sections from SAL animals) were excluded from the analysis.

The method of analysis used for the electron microscopic examination in the present study was based on our previous studies (Hanson and Smith, 1999, 2002; Hanson et al., 2004; Kuwajima et al., 2004). In the sections processed for immunoperoxidase labeling, the tissue was sampled randomly from at least three different animals for each group I mGluR subtype. Electron micrographs of GP and STN were randomly taken at 25,000 $\times$ from ultrathin sections close enough to the surface of each section that antibody penetration was optimal. All labeled elements in an area of observation were counted, and the total area of observation was measured to calculate densities of labeled elements. Any elements that were not identifiable because of a lack of well defined ultrastructural features were categorized as "unknown." These unknown elements most likely consisted predominantly of small-caliber dendrites, unmyelinated axons, and glial cell processes. A total area from which observations were made is summarized in Table 2.

In the sections processed for preembedding immunogold labeling, electron micrographs of GP and STN dendrites were taken at 31,500 and $40,000 \times$ from the surface of immunostained sections, where the labeling was optimal. The gold particles were then counted and classified into four categories (intracellular, synaptic, perisynaptic, and extrasynaptic) based on their localization in relation to the plasma membrane and postsynaptic specializations visible in the plane of section. The gold particles that were apposed to or within $20 \mathrm{~nm}$ from the plasma membrane were classified as "plasma membrane bound" and pooled into three categories (i.e., synaptic, perisynaptic, and extrasynaptic) based on their localization relative to postsynaptic specializations. The term "synaptic" is used to describe gold particles found within or apposed to the main body of postsynaptic specializations, whereas "perisynaptic" refers to regions of the plasma membrane within $20 \mathrm{~nm}$ from the edges of postsynaptic specializations. All other plasma membrane-bound gold particles were categorized as "extrasynaptic." The gold particles that were located $>20 \mathrm{~nm}$ away from the plasma membrane were categorized as "intracellular." The $20 \mathrm{~nm}$ cutoff point was chosen based on the assertion that the distance between the epitope and gold particle, bridged by the primary and secondary antibodies, can be $\sim 20 \mathrm{~nm}$ (Blackstad et al., 1990). Dendrites with poor ultrastructural preservation or cut in a plane of section that was not suitable to distinguish the presynaptic and postsynaptic membranes were omitted from the analysis. Micrographs of randomly selected dendrites (9-11 per brain area per animal) were analyzed for total length of dendritic plasma membrane and length of synaptic and perisynap- 
Table 2. Summary of total areas (in $\mu \mathrm{m}^{2}$ ) and number of animals (in parentheses) used for EM immunoperoxidase localization of $\mathrm{mGluR1a}$ and $\mathrm{mGluR5}$ in the mouse $\mathrm{GP}$ and STN

\begin{tabular}{|c|c|c|c|c|}
\hline \multirow[b]{2}{*}{ Genotype-treatment } & \multicolumn{2}{|l|}{ GP } & \multicolumn{2}{|l|}{ STN } \\
\hline & mGluR1a & mGluR5 & mGluR1a & mGluR5 \\
\hline H1wt-SAL & $1432.67(3)$ & $1078.07(3)$ & $941.76(3)$ & $895.10(3)$ \\
\hline H1wt-MPTP & $1463.82(3)$ & $975.95(3)$ & $1139.95(3)$ & $1124.33(3)$ \\
\hline H1ko-SAL & $1047.80(3)$ & $916.93(3)$ & $854.57(3)$ & $1151.91(3)$ \\
\hline H1ko-MPTP & $1396.88(3)$ & $1053.53(3)$ & $1178.05(3)$ & $1244.41(3)$ \\
\hline H2wt-SAL & $913.32(3)$ & $989.34(3)$ & $1226.49(4)$ & 908.89 (3) \\
\hline H2wt-MPTP & $1135.25(3)$ & $964.64(3)$ & $1330.74(3)$ & $938.76(3)$ \\
\hline H2ko-SAL & $1058.84(3)$ & $1159.87(3)$ & $1015.17(3)$ & $990.13(3)$ \\
\hline H2ko-MPTP & $1255.32(3)$ & $1066.15(3)$ & $1151.65(3)$ & 1146.16 (3) \\
\hline
\end{tabular}

A

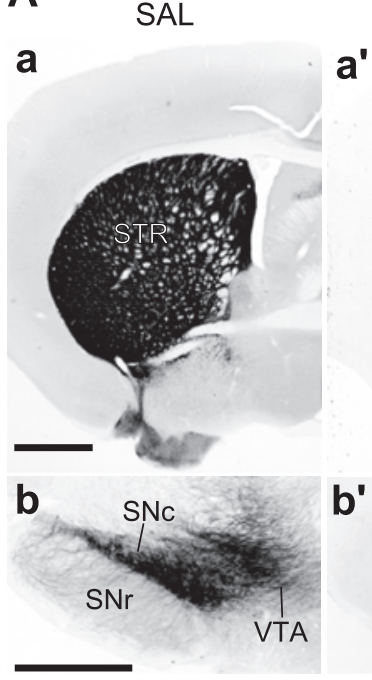

MPTP

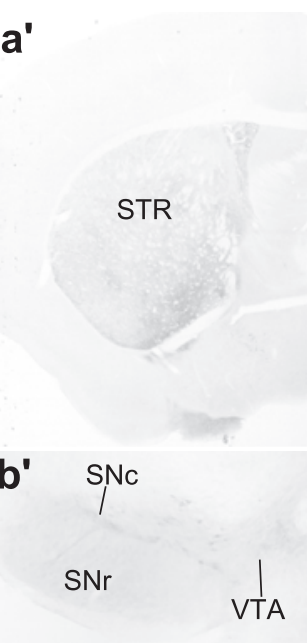

SAL

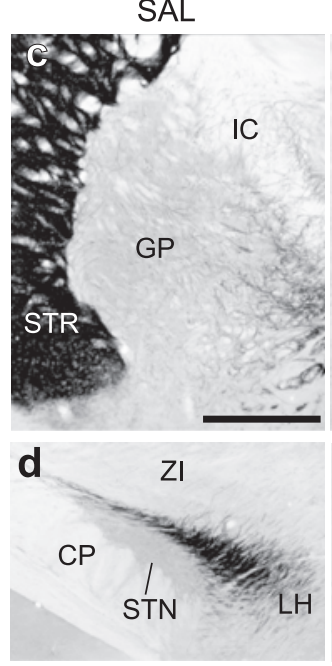

MPTP

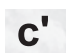

IC

B

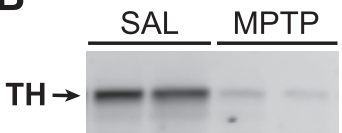

GP

STR
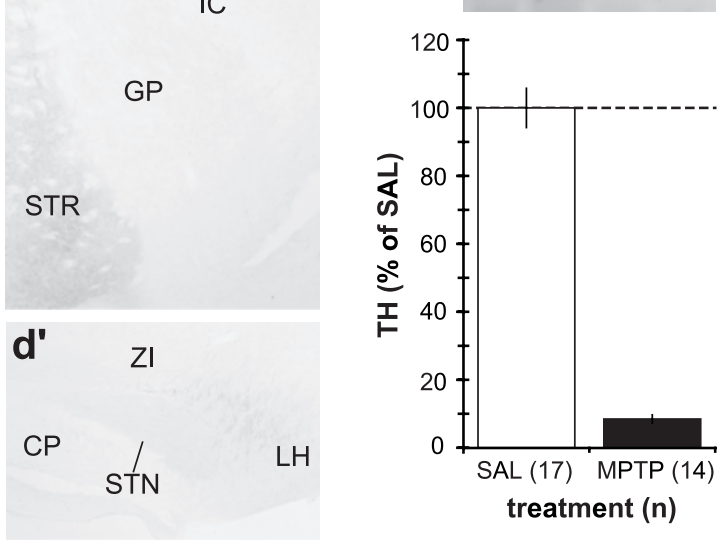

Figure 1. Light microscopic immunoperoxidase and Western immunoblot analyses of TH in the striatum, GP, and STN of MPTP-treated mice. A, Representative light micrographs of DATimmunostained basal ganglia tissue sections from SAL- and MPTP-treated mice. In STR $\left(\boldsymbol{a}, \boldsymbol{a}^{\prime}\right), \mathrm{GP}\left(\boldsymbol{c}, \boldsymbol{c}^{\prime}\right)$, and $\operatorname{STN}\left(\boldsymbol{d}, \boldsymbol{d}^{\prime}\right)$, MPTP treatment resulted in the loss of DAT-labeled dopaminergic fibers.

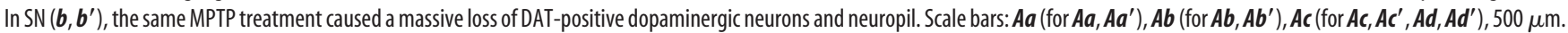
CP, Cerebral peduncle; IC, internal capsule; LH, lateral hypothalamus; $S \mathrm{Nc}$, substantia nigra pars compacta; $\mathrm{SNr}$, substantia nigra pars reticulata; VTA, ventral tegmental area; Zl, zona incerta. $\boldsymbol{B}$, Top, A representative immunoblot of the striatal tissue samples from two SAL-treated and two MPTP-treated mice, demonstrating a profound decrease in the expression level of TH, a marker for dopaminergic terminals. Bottom, Quantification of the intensity of TH-immunoreactive bands from SAL- $(n=17)$ and MPTP-treated $(n=14)$ mice, expressed as mean \pm SEM. Note that the MPTP treatment causes $>90 \%$ reduction in $\mathrm{TH}$ level on average.

tic plasma membrane using the ImageJ software (with the DM3 Reader plug-in; version 1.3.4; available the ImageJ website).

Effects of MPTP treatment and Homer deletion on the subcellular and subsynaptic localization of group I mGluRs were statistically analyzed by two-way ANOVA, with post hoc Tukey test. Friedman's test was used if a dataset did not fit the Gaussian distribution. H1ko and H2ko were compared with their respective wild types.

\section{Results}

\section{MPTP-induced lesion of the dopaminergic system in the} basal ganglia

In saline-treated mice, dense DAT immunoreactivity was observed in STR (Fig. 1 $A a$ ) and substantia nigra (SN) (Fig. 1 $A b$ ). DAT-labeled axon collaterals were also seen in GP (Fig. 1 Ac) and STN (Fig. $1 B d$ ), as described previously (for review, see Smith and Kieval, 2000). As a model of Parkinson's disease, we used the dopamine-specific neurotoxin MPTP to induce lesion of the nigrostriatal dopaminergic system. This treatment resulted in a massive loss of DAT-immunoreactive profiles in the STR, SN, GP, and STN (Fig. $1 A a^{\prime}, A b^{\prime}, A c^{\prime}, A d^{\prime}$ ). Quantitative Western immunoblot analysis of TH expression in the STR revealed $\sim 90 \%$ reduction after MPTP treatment (Fig. $1 B$ ). There was no marked difference between wild-type and Homer-deficient mice in the extent of MPTP-induced lesion of the nigrostriatal dopaminergic projection (data not shown).

Biochemical measurements of expression levels of group I mGluRs and Homer proteins in striatum and GP of MPTP-treated mice

To assess changes in the expression levels of group I mGluRs and Homer proteins in basal ganglia, Western immunoblots were used to measure mGluR1a, mGluR5, long Homer, and Homerla protein levels in the striatum and GP of MPTP-treated mice. Because of the small size of the STN, we could not collect enough STN tissue for this part of the study. MPTP treatment caused a statistically significant reduction in expression levels of mGluRla and H1a proteins in the STR (Fig. $2 A)(p<0.01 ; t$ test), whereas the levels of long Homer (e.g., H1b/c, H2, and H3) and mGluR5 proteins were unaffected (Fig. $2 \mathrm{~A}$ ). In contrast, expression levels of group I mGluRs and Homer proteins in GP were unaffected by the same treatment (Fig. 2B).

Light microscopic immunohistochemical Homer staining in GP and STN of MPTP-treated mice

At the light microscopic level, no obvious change in the pattern and intensity of $\mathrm{H} 1 \mathrm{~b} / \mathrm{c}$ ir was found in GP and STN after MPTP 
A. STR
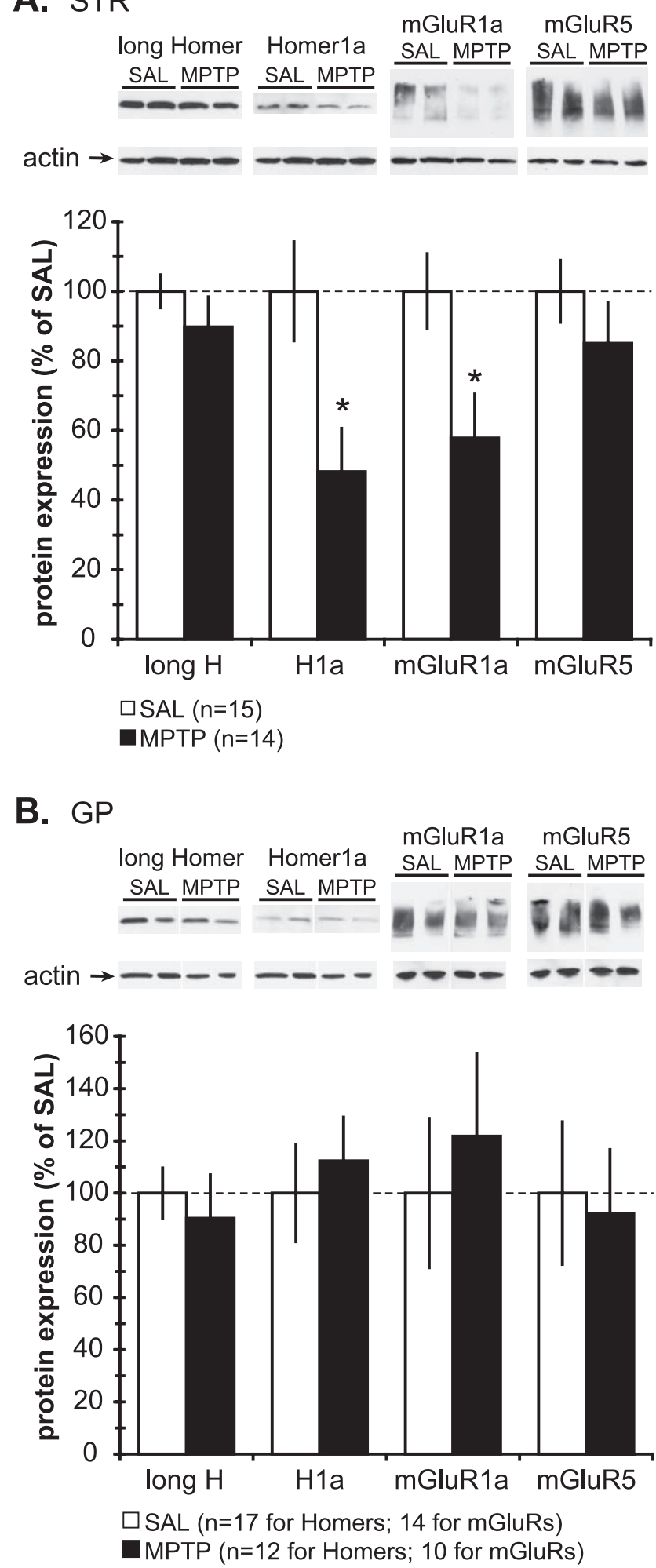

Figure 2. Western immunoblot analysis of the total tissue expression levels of group I mGluRs and Homer proteins in the STR and GP of saline- and MPTP-treated mice. $\boldsymbol{A}$, Top, Representative immunoblots of the striatal tissue samples from two SAL-treated and two MPTP-treated mice, probed for (from left) long Homer, H1a, mGluR1a, and mGluR5. The molecular weights of long Homer and $\mathrm{H} 1 \mathrm{a}$ were $\sim 45 \mathrm{kDa}$ and $\sim 27 \mathrm{kDa}$, respectively. Both mGluR1a and mGluR5 migrated as monomers and multimers with the molecular weight ranging from $\sim 130$ to $\sim 250 \mathrm{kDa}$. Actin was used as loading control and was unaffected by MPTP treatment. Note that the intensity of immunoreactive bands for H1a and mGluR1a in the MPTP mice is less than the saline-treated mice. Bottom, Quantification of the intensity of immunoreactive bands from the striatal samples from SAL- $(n=15)$ and MPTP-treated $(n=14)$ mice. All treatment, $\mathrm{H} 2$ deletion, or both (Fig. $3 B a-B d, D a-D d$ ). Similarly, neither MPTP nor $\mathrm{H} 1$ deletion significantly affected the pattern and intensity of $\mathrm{H} 2$ ir in GP (Fig. 3Ae-Ah) and STN (Fig. 3Ce$\mathrm{Ch}$ ). In all groups, very light or no immunoreactivity for $\mathrm{H} 3$ protein was found in GP and STN (data not shown). This is consistent with previous observations that $\mathrm{H} 3$ expression is restricted to the cerebellum, hippocampus, and olfactory bulb (Sun et al., 1998; Xiao et al., 1998; Shiraishi et al., 2004). The lack of immunoreactivity for $\mathrm{H} 1$ and $\mathrm{H} 2$ in their corresponding knockout animals indicates the high specificity of the anti-H1b/c and anti-H2 antibodies, respectively, used in this study.

\section{LM immunoperoxidase localization of group I mGluRs in GP and STN}

At the light microscopic level, immunoreactivity for mGluR1a and mGluR5 in the GP and STN of H1 and H2 mice (both wildtype and knock-out) did not exhibit any marked difference between SAL and MPTP groups. Consistent with previous observations in the monkey pallidum and STN (Hanson and Smith, 1999; Kuwajima et al., 2004), both perikarya and neuropil contained intense labeling for group I mGluRs (Figs. 4A,E, 5A,E).

\section{EM immunoperoxidase localization of group I mGluRs in GP and STN}

MPTP treatment increases presynaptic localization of mGluR1a, but not mGluR5, in GP and STN

In all genotype and treatment groups, dendrites and unmyelinated axons accounted for the largest number of immunoreactive elements in mGluR1a- and mGluR5-immunostained GP and STN tissue. In some cases, axonal group I mGluR ir was found as discrete patches along the length of unmyelinated axons (Fig. $4 B)$. Immunoreactive terminal boutons for either receptor subtypes were rarely encountered (Figs. $4 B, E, 5 B, E$ ). MPTP treatment significantly increased the relative density of mGluRlalabeled presynaptic elements in the GP and STN of wild-type mice. More specifically, a statistically significant increase in the density of mGluR1a-labeled axon terminals was found in the GP of both H1wt and H2wt (Fig. $4 C, D$, term.) ( $p<0.05$; Tukey test), whereas an increased density of mGluR1a-labeled unmyelinated axons was found in the STN of H2wt (Fig. $4 H$, u.ax.) ( $p<0.05$ between H2wt-SAL and H2wt-MPTP; Tukey test). Although the density of u.ax. was also increased in the GP of H2wt-MPTP, it did not reach statistical significance (Fig. $4 D$, u.ax.) $(p=0.07$; Tukey test). Neither MPTP treatment nor Homer deletion significantly altered the overall pattern of mGluR5 localization in neuronal elements of the GP and STN neuropil in these mice (Fig. 5).

MPTP treatment and Homer deletion alter glial expression of group I mGluRs in GP and STN

Overall, the density of mGluR5-labeled glial processes in both GP and STN was higher (on average, $5.99 \pm 0.86$ and $6.79 \pm 0.97$ per

$\leftarrow$

values are normalized to the saline-treated group and expressed as mean \pm SEM. Note that MPTP treatment causes $\sim 50 \%$ and $\sim 40 \%$ reduction in H1a and mGluR1a levels, respectively $\left({ }^{*} p<0.05 ; t\right.$ test). $B$, Top, Representative immunoblots of GP tissue samples from two SALtreated and two MPTP-treated mice, probed for (from left) long Homer, H1a, mGluR1a, and mGluR5. Note that the intensity of immunoreactive bands for Homer proteins and group I mGluRs is not altered by MPTP treatment. Bottom, Quantification of the intensity of immunoreactive bands from the striatal samples from SAL- $(n=15)$ and MPTP-treated $(n=14)$ mice reveals that MPTP treatment had no effect on the expression levels of Homer proteins and group I mGluRs in GP. All values are normalized to the saline-treated group and expressed as mean \pm SEM. 
$100 \mu \mathrm{m}^{2}$ for GP and STN, respectively) than that of mGluRla-labeled glial elements (on average $1.94 \pm 0.36$ and $2.77 \pm$ 0.41 per $100 \mu \mathrm{m}^{2}$ for GP and STN, respectively).The glial expression of mGluRla and mGluR5 ir was affected by MPTP treatment and Homer deletion in the GP and STN. MPTP treatment significantly increased the density of mGluRla-labeled glial processes in the GP of H2wt, but not H2ko, mice (Fig. $4 D$, glia) $(p<0.05$; Tukey test). In addition, the density of mGluR5-labeled glial processes in the GP significantly decreased after deletion of H1 (Fig. 5C, glia) $(p<0.05$ between H1wt-SAL and H1ko-SAL; Tukey test), which was reversed by MPTP treatment (Fig. $5 C$, glia) $(p<0.05$ between H1koSAL and H1ko-MPTP; Tukey test).

\section{Immunogold localization of group I mGluRs in GP and STN \\ $m$ GluR $1 a$ and $m$ GluR5 are differentially expressed in dendrites of GP and \\ STN neurons}

Because of its diffuse and amorphous nature, the immunoperoxidase reaction product does not reveal the exact subsynaptic localization of receptors. To address this issue, we used the preembedding immunogold method at the electron microscopic level, which offers a much higher level of spatial resolution.

Most (60-70\%) of the mGluR1a immunogold labeling was associated with the dendritic plasma membrane, whereas only $\sim 35 \%$ of mGluR5 labeling was apposed to the plasma membrane (Fig. $6 C, D)$. Neither Homer deletion nor MPTP treatment had a significant effect on the relative proportions of mGluRla and mGluR5 expressed on the plasma membrane of GP dendrites in $\mathrm{H} 1$ and $\mathrm{H} 2$ mice (both wild-type and knock-out) (Fig. 6C,D). Of the membrane-bound labeling for mGluR1a and mGluR5, most (75-85\%) was found in the extrasynaptic portion of the plasma membrane. Most of the synapse-associated labeling was found within the postsynaptic specialization of symmetric synapses (40-70\% of synapseassociated particles) (Fig. $6 A, B$ ) or at the edges of symmetric $(20-40 \%)$ (Fig. $6 B$ ) and asymmetric (10-20\%) (Fig. 6A) postsynaptic specializations, whereas $<5 \%$ of total plasma membrane-bound group I mGluRs labeling was found within the asymmetric postsynaptic densities.

Similar to GP, $60-65 \%$ of total immunogold labeling for mGluRla in STN dendrites of $\mathrm{H} 1$ and $\mathrm{H} 2$ mice (both wild-type and knock-out) was associated with the plasma membrane, whereas $35-40 \%$ of

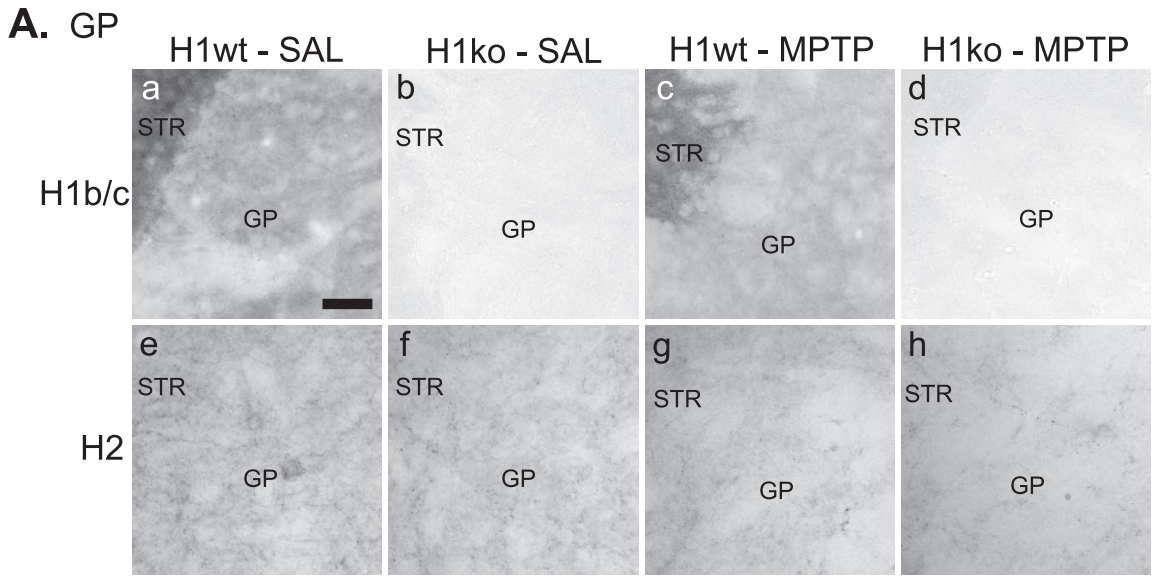

B. GP
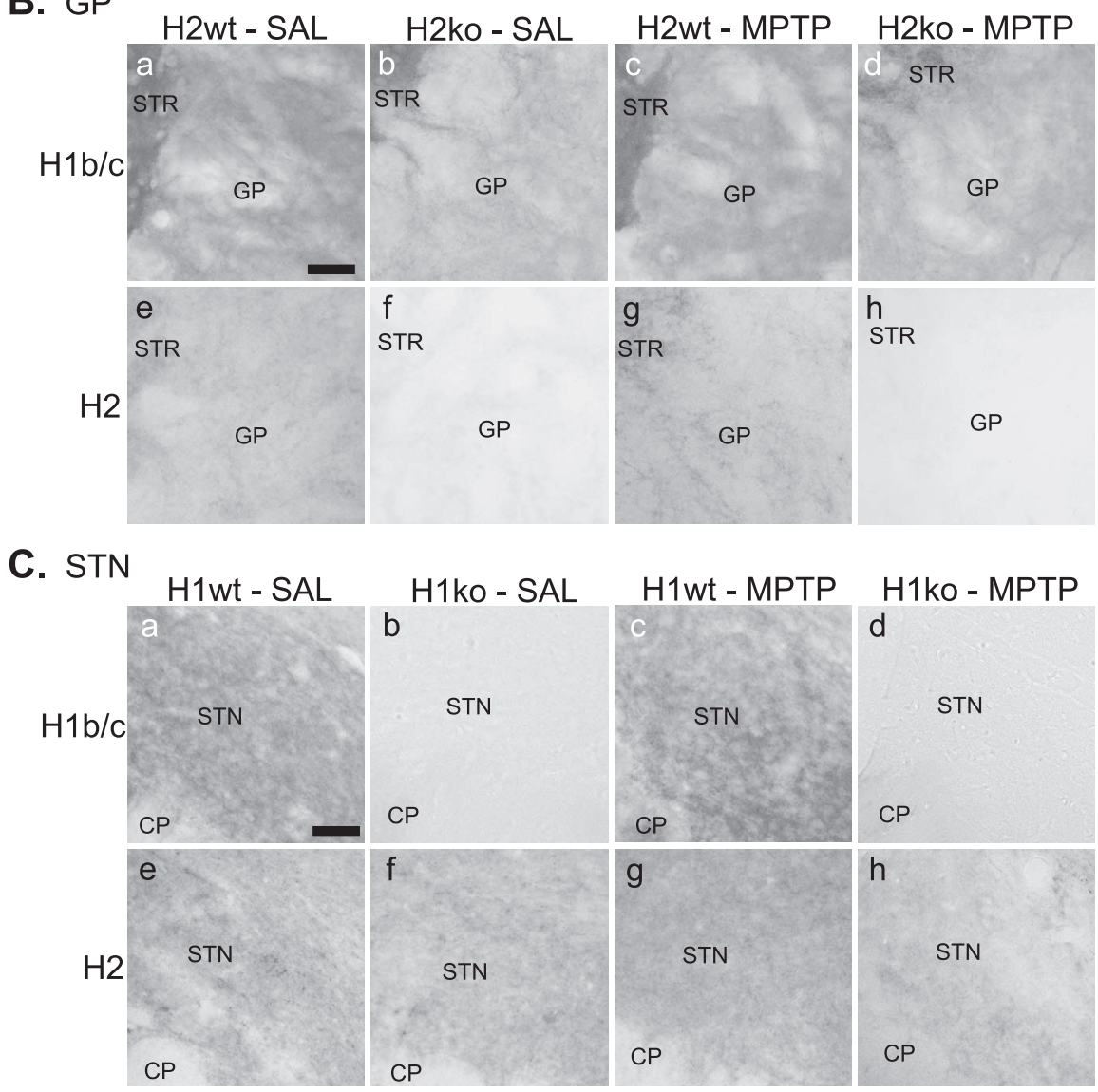

D. STN
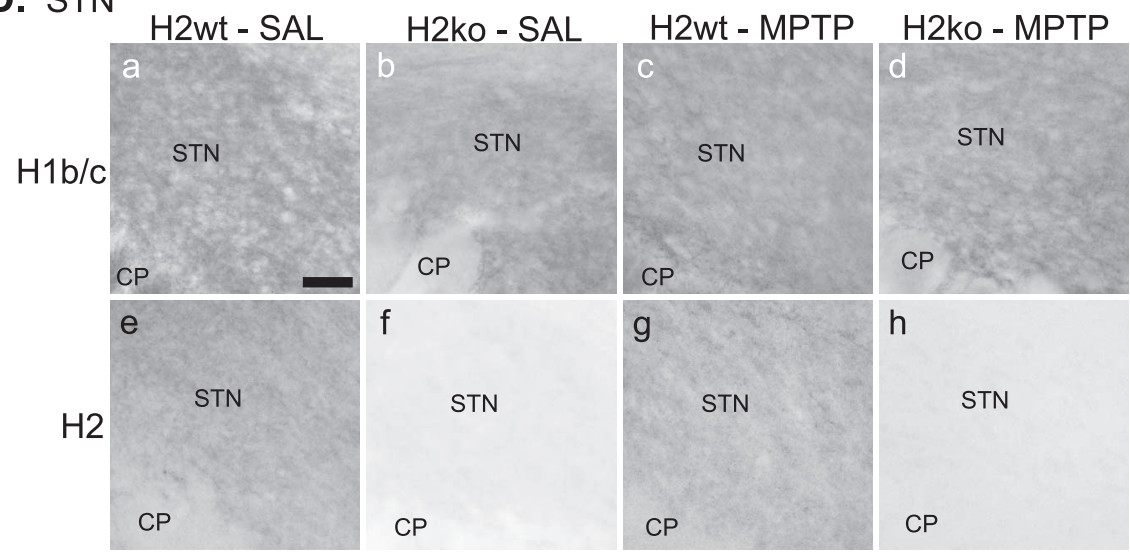

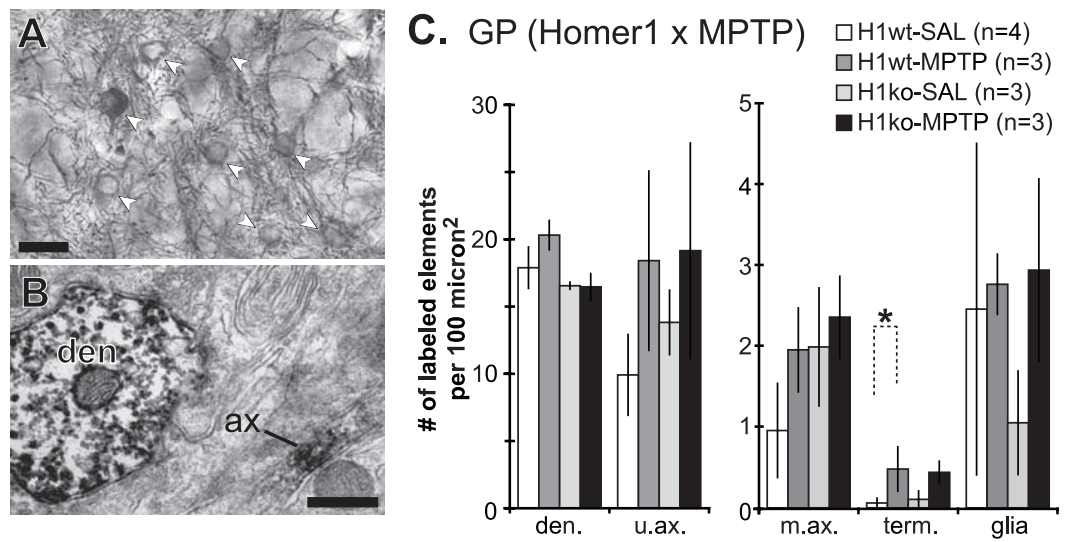

\section{GP (Homer2 x MPTP)}
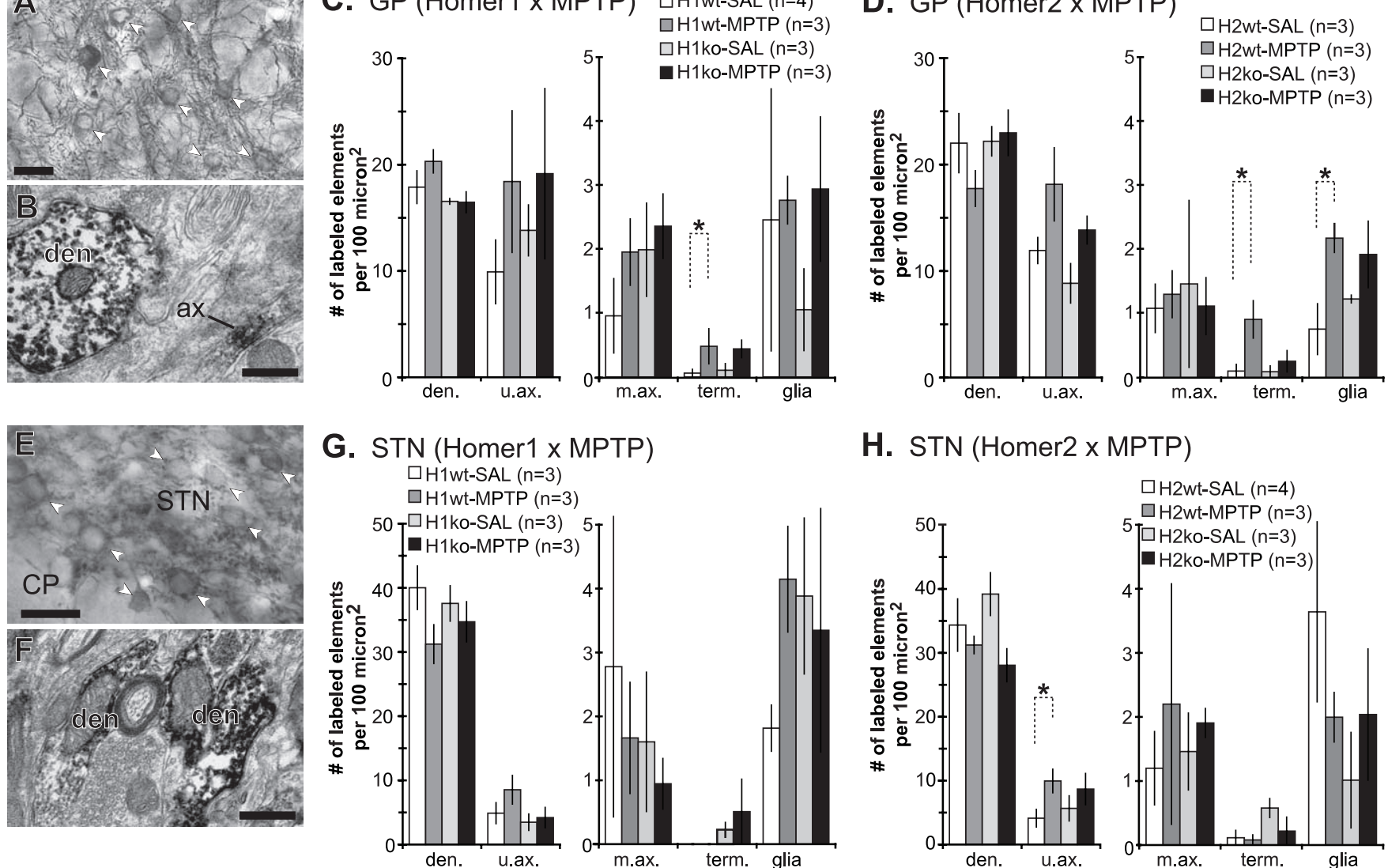

\section{H. STN (Homer2 x MPTP)}

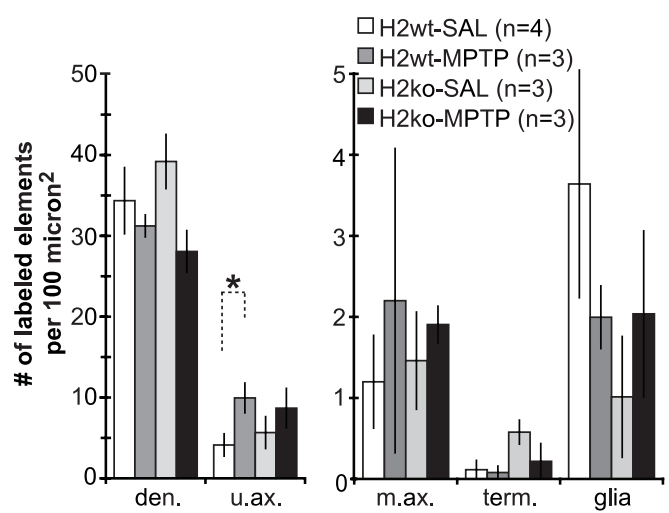

Figure 4. LM and EM immunoperoxidase localization of mGluR1a in GP and STN of wild-type and Homer-deficient mice treated with MPTP or saline. A, Immunoperoxidase labeling for mGluR1a in GP at light microscopic level shows densely stained neuropil and perikarya (white arrowheads). $\boldsymbol{B}$, Immunoreactivity for mGluR1a is mainly expressed in dendrites and unmyelinated axons. Note that mGluR1a labeling in a longitudinally cut unmyelinated axon (ax) appears as a discrete patch of peroxidase reaction product along the length of the axon. $\boldsymbol{C}, \boldsymbol{D}$, Histograms summarizing the subcellular localization of mGluR1a in GP neuropil of Homer1 $(\boldsymbol{C})$ and Homer2 (D) mice, expressed as the mean \pm SEM density of labeled elements per $100 \mu \mathrm{m}^{2}$ of GP tissue. Note that statistically significant differences were found in the density of mGluR1a-immunopositive axon terminals ( $\boldsymbol{C}, \boldsymbol{D}$, term.; ${ }^{*} p<0.05$; Tukey test) and that of mGluR1a-labeled glial processes ( $\boldsymbol{D}$, glia; ${ }^{*} p<0.05$; Tukey test). $\boldsymbol{E}$, Immunoperoxidase labeling for mGluR1a in STN at light microscopic level shows densely stained neuropil and perikarya (white arrowheads). $\boldsymbol{F}$, Immunoreactivity for mGluR1a is mainly expressed in dendrites, with occasional labeling in unmyelinated axons. $\boldsymbol{G}, \boldsymbol{H}$, Histograms summarizing the subcellular localization of mGluR1a in STN neuropil of Homer1 ( $\boldsymbol{G}$ ) and $\mathrm{Homer2}(\boldsymbol{H})$ mice, expressed as the mean \pm SEM density of labeled elements per $100 \mu \mathrm{m}^{2}$ of STN tissue. Note that statistically significant differences were found in the density of mGluR1a-immunopositive unmyelinated axons ( $\boldsymbol{H}$, u.ax.; ${ }^{*} p<0.05$; Tukey test). CP, Cerebral peduncle; den, dendrites; u.ax., unmyelinated axons; m.ax., myelinated axons; term., terminal boutons; glia, glial processes. Scale bars: $A, E, 50 \mu \mathrm{m} ; \boldsymbol{B}, \boldsymbol{F}, 0.5 \mu \mathrm{m}$.

mGluR5 labeling was found on the membrane (Fig. 6G,H). Of the plasma membrane-bound mGluR1a and mGluR5 labeling, $\sim 95 \%$ was extrasynaptic. Of the synapse-associated labeling, most of the group I mGluRs were found within the postsynaptic specialization of symmetric synapses $(20-35 \%$ of synapseassociated particles) or at the edges of symmetric $(30-45 \%)$ (Fig. $6 E$ ) and asymmetric (25-35\%) (Fig. 6E, F) postsynaptic special- izations, whereas mGluR5 labeling within the asymmetric postsynaptic density was rare $(<5 \%)$.

\section{Group I $m G l u R s$ are selectively concentrated in perisynaptic} plasma membrane in GP and STN

To assess the degree of selective concentration of receptors at synapse-associated plasma membrane domains, we calculated the relative density $(\mathrm{RD})$ of gold labeling. This was achieved by dividing the percentage of gold particles associated with synaptic and perisynaptic membrane by the proportion of the length of the dendritic plasma membrane involved in these synaptic domains. From 24 mice $(n=3$ for each genotype-treatment group), we examined 248 randomly selected group I mGluRs-containing dendrites in the GP and 261 labeled dendrites in the STN. In the GP, $\sim 7 \%$ of the dendritic plasma membrane was accounted for by symmetric synapses, $\sim 3 \%$ by asymmetric synapses, $\sim 2 \%$ by the perisynaptic plasma
Figure 3. LM immunoperoxidase labeling for Homer proteins in GP and STN of wild-type and Homer-deficient mice treated with MPTP or saline. $\boldsymbol{A}$, Immunoreactivity for Homer proteins in the GP of $\mathrm{H} 1$ mice. $\boldsymbol{a}-\boldsymbol{d}, \mathrm{H} 1 \mathrm{~b} / \mathrm{c}$ protein is comparably expressed the anti-H1b/c antibody. $\boldsymbol{e}-\boldsymbol{h}$, The pattern and intensity of $\mathrm{H} 2$ ir in GP did not show marked alteration by MPTP treatment and/o $\mathrm{H} 1$ deletion. $\boldsymbol{B}$, Immunoreactivity for Homer proteins in the $\mathrm{GP}$ of $\mathrm{H} 2$ mice. $\boldsymbol{a}-\boldsymbol{d}$, The pattern and intensity of $\mathrm{H} 1 \mathrm{~b} / \mathrm{c}$ ir in GP did not show marked alteration by MPTP treatment and/or $\mathrm{H} 2$ deletion. $\boldsymbol{e}-\boldsymbol{h}, \mathrm{H} 2$ protein is comparably expressed in the neuropil of GP in saline-treated $(\boldsymbol{e})$ and MPTP-treated $(\boldsymbol{g}) \mathrm{H} 2 \mathrm{wt}$. The lack of $\mathrm{H} 2$ ir in $\mathrm{H} 2 \mathrm{ko}(\boldsymbol{f}, \boldsymbol{h})$ indicates the specificity of the anti-H2 antibody. $\boldsymbol{C}$, Immunoreactivity for Homer proteins in the STN of $\mathrm{H} 1$ mice. $\boldsymbol{a}-\boldsymbol{d}, \mathrm{H} 1 \mathrm{~b} / \mathrm{c}$ protein is comparably expressed in the neuropil of STN in saline-treated ( $\boldsymbol{a}$ ) and MPTP-treated ( $\boldsymbol{c}$ ) H1wt. $\boldsymbol{e}-\boldsymbol{h}$, The pattern and intensity of $\mathrm{H} 2$ ir in STN did not show marked alteration by MPTP treatment and/or $\mathrm{H} 1$ deletion. $\boldsymbol{D}$, Immunoreactivity for Homer proteins in the STN of $\mathrm{H} 2$ mice. $\boldsymbol{a}-\boldsymbol{d}$, The pattern and intensity of $\mathrm{H} 1 \mathrm{~b} / \mathrm{c}$ ir in STN did not show marked alteration by MPTP treatment and/or $\mathrm{H} 2$ deletion. $\boldsymbol{e}-\boldsymbol{h}, \mathrm{H} 2$ protein is comparably expressed in the neuropil of STN in saline-treated (e) and MPTP-treated ( $\boldsymbol{g}$ ) H2wt. Scale bars: $\boldsymbol{A a}$ (for $\boldsymbol{A a}-\boldsymbol{A h}), \boldsymbol{B a}($ for $\boldsymbol{B a}-\boldsymbol{B h}), \mathbf{C a}$ (for $C a-C h), D a(D a-D h), 50 \mu \mathrm{m}$. CP, Cerebral peduncle. 


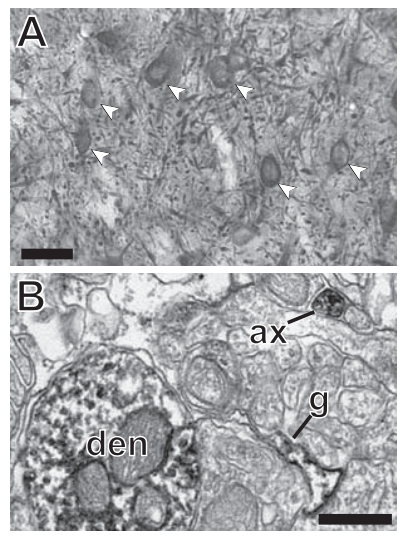

\section{GP (Homer1 x MPTP)}

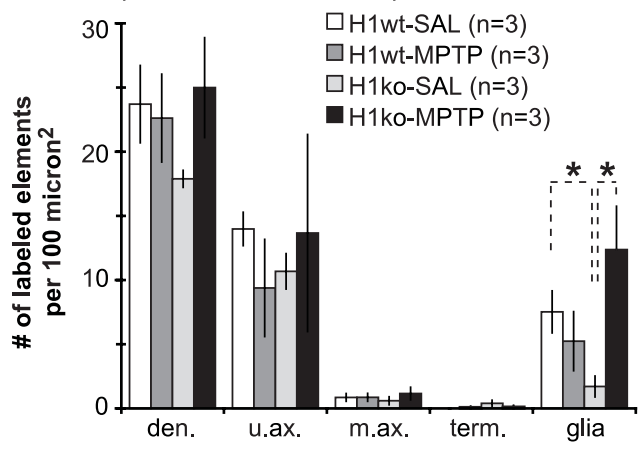

D. GP (Homer2 x MPTP)
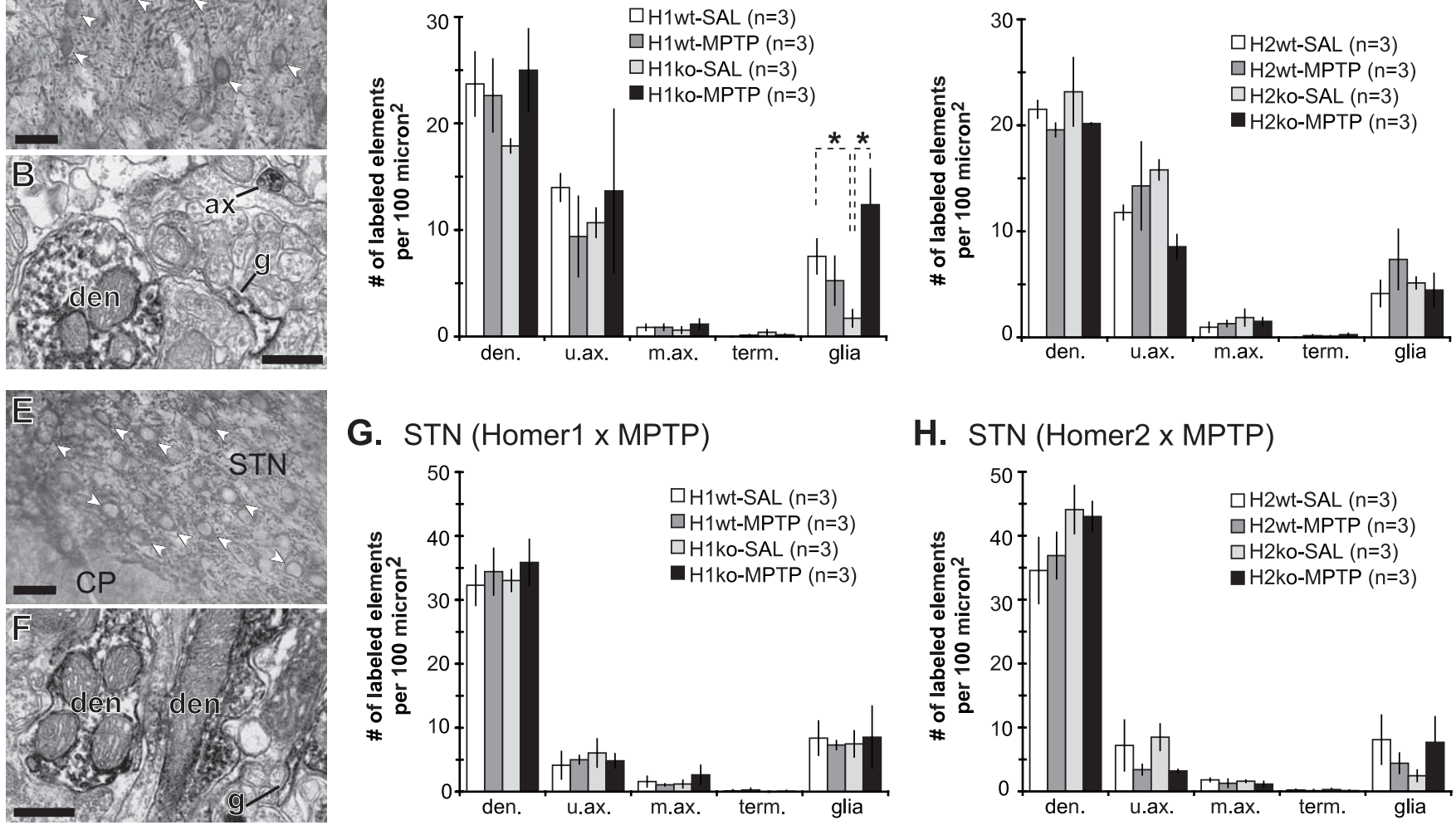

G. STN (Homer1 x MPTP)

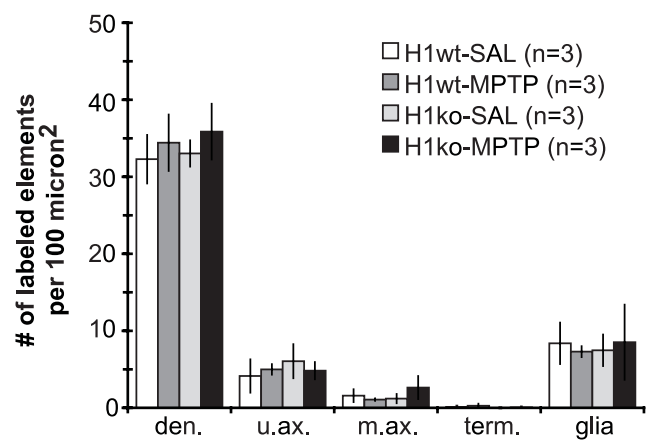

H. STN (Homer2 x MPTP)

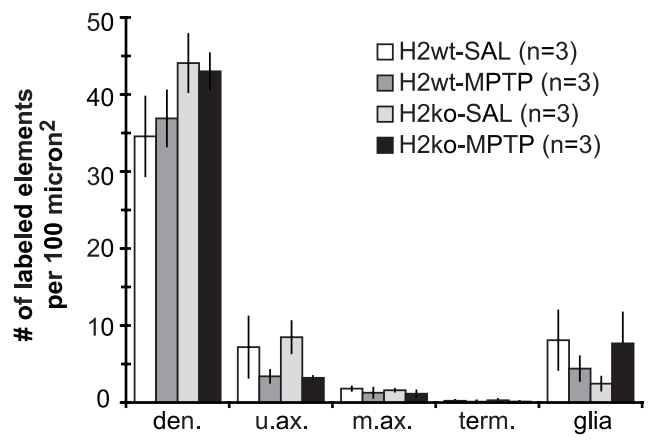

Figure 5. LM and EM immunoperoxidase localization of mGluR5 in GP and STN of wild-type and Homer-deficient mice treated with MPTP or saline. $A$, Immunoperoxidase labeling for mGluR5 in GP at light microscopic level shows densely stained neuropil and perikarya (white arrowheads). $\boldsymbol{B}$, Immunoreactivity for mGluR5 is mainly expressed in dendrites, unmyelinated axons (ax), and glial processes (g). $\boldsymbol{C}, \boldsymbol{D}$, Histograms summarizing the subcellular localization of mGluR5 in GP neuropil of Homer1 $(\boldsymbol{C})$ and Homer2 (D) mice, expressed as the mean \pm SEM density of labeled elements per $100 \mu \mathrm{m}^{2}$ of GP tissue. Note that statistically significant differences were found in the density of mGluR5-labeled glial processes (C, glia; ${ }^{*} p<0.05 ;$ Tukey test). $\boldsymbol{E}$, Immunoperoxidase labeling for mGluR5 in STN at light microscopic level shows densely stained neuropil and perikarya (white arrowheads). $\boldsymbol{F}$, Immunoreactivity for mGluR5 is mainly expressed in dendrites, with occasional labeling in glial processes $(\mathrm{g}) . \mathbf{G}, \boldsymbol{H}$, Histograms summarizing the subcellular localization of mGluR5 in STN neuropil of Homer $\mathbf{(} \boldsymbol{G})$ and Homer2 $(\boldsymbol{H})$ mice, expressed as the mean \pm SEM density of labeled elements per $100 \mu \mathrm{m}^{2}$ of STN tissue. CP, Cerebral peduncle; den, dendrites; u.ax., unmyelinated axons; m.ax., myelinated axons; term., terminal boutons; glia, glial processes. Scale bars: $A, E, 50 \mu \mathrm{m} ; \boldsymbol{B}, \boldsymbol{F}, 0.5 \mu \mathrm{m}$.

membrane (i.e., $20 \mathrm{~nm}$ from the edges of postsynaptic specializations) at symmetric synapses, $\sim 0.5 \%$ by the perisynaptic membrane at asymmetric synapses, and $\sim 87 \%$ by the extrasynaptic plasma membrane. Neither Homer deletion nor MPTP treatment had a significant effect on the percentage of the dendritic plasma membrane at each synaptic domain in GP (data not shown). If the plasma membrane-bound receptor immunolabeling was randomly distributed, then one would expect to find percentages of immunogold particles associated with synaptic and perisynaptic membrane in the same range as that revealed by random plasma membrane measurements (therefore, the RD of gold particles would be equal to one). However, such was not the case. Immunogold labeling for both mGluR1a and mGluR5 was highly concentrated at the perisynaptic plasma membrane of asymmetric synapses (Fig. $7 A-D$, peri-asym), and to a lesser degree, of symmetric synapses (Fig. $7 A-D$, peri-sym). In contrast, a very low RD of mGluRla and mGluR5 was found within the asymmetric postsynaptic density (Fig. 7A-D, syn-asym). Despite the preponderance of labeling for group I mGluRs within the postsynaptic specialization of symmetric synapses, $\mathrm{RD}$ was rather low, ranging from 1.0 to 3.0 (Fig. 7A-D, syn-sym).

In the STN, $2-3 \%$ of the dendritic plasma membrane was occupied by symmetric synapses, $1-2 \%$ by asymmetric synapses, $\sim 1 \%$ by perisynaptic plasma membranes at symmetric synapses, $\sim 0.3 \%$ by perisynaptic membranes at asymmetric synapses, and $\sim 95 \%$ by extrasynaptic membrane. Neither Homer deletion nor MPTP treatment had a significant effect on this breakdown of synaptic domains of the dendritic plasma membrane in the STN (data not shown). Analysis of RD of group I mGluRs revealed that both mGluR1a and mGluR5 were highly concentrated in the perisynaptic plasma membrane at asymmetric (Fig. $7 E-H$, periasym) and, to a lesser degree, symmetric (Fig. $7 E-H$, peri-sym) synapses. The mean receptor $\mathrm{RD}$ remained $<1.0$ for both mGluR1a and mGluR5 within the postsynaptic specialization of symmetric and asymmetric synapses in all treatment groups (Fig. $7 E-H$, syn-sym and syn-asym, respectively).

\section{MPTP treatment increases $m G l u R 1 a$ within symmetric synapses} in GP and STN

In H1wt and H1ko mice, MPTP treatment significantly increased the RD of mGluRla within symmetric synapses in both GP (Fig. $7 A$, syn-sym) ( $p<0.01$ between H1wt-SAL and H1wt-MPTP; $p<0.05$ between H1ko-SAL and H1ko-MPTP; Tukey test) and STN (Fig. $7 C$, syn-sym) ( $p<0.05$ between H1wt-SAL and H1wtMPTP; Tukey test). In contrast, MPTP treatment significantly reduced $\mathrm{RD}$ for the extrasynaptic mGluRla in the GP of H1ko (Fig. 7A, extrasyn) $(p<0.05$ between H1ko-SAL and H1koMPTP; Tukey test). 


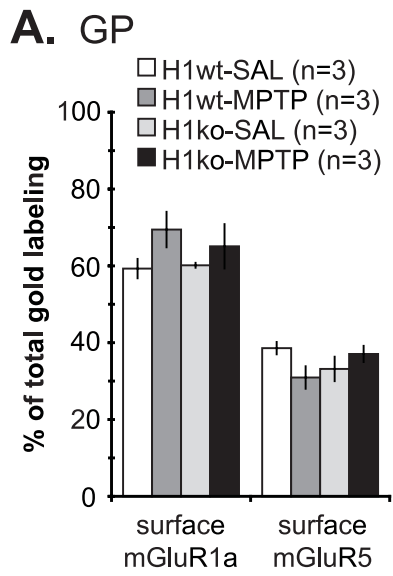

E. STN

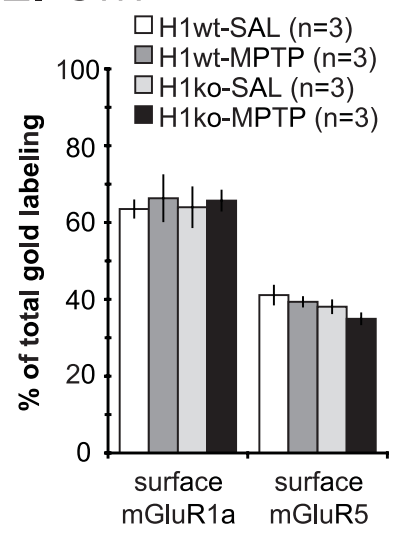

B. GP
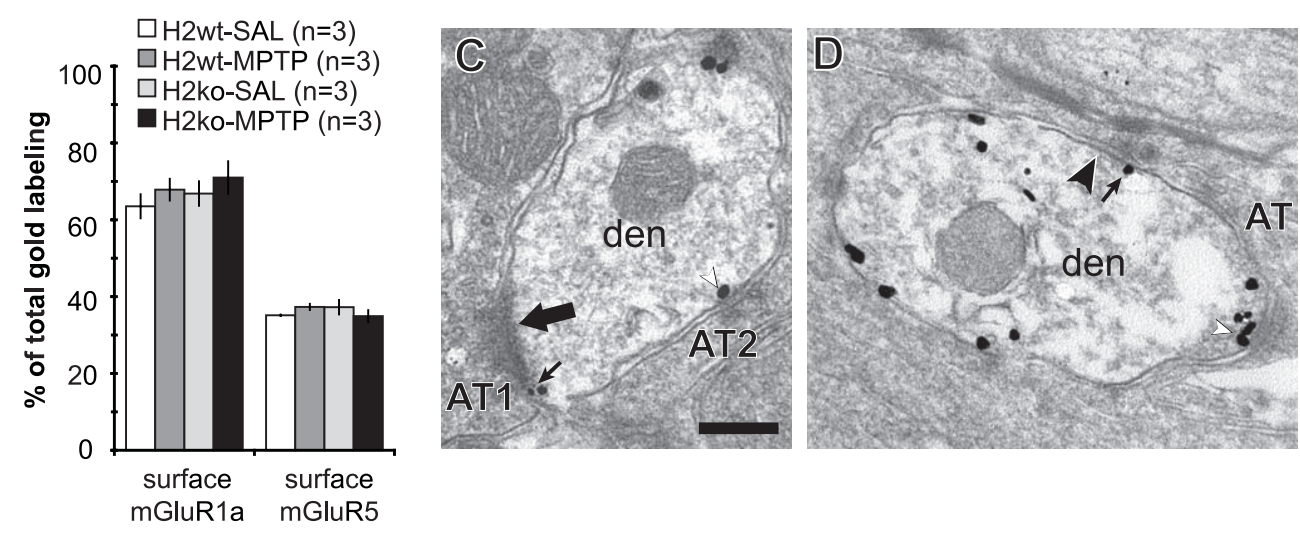

\section{F. STN}

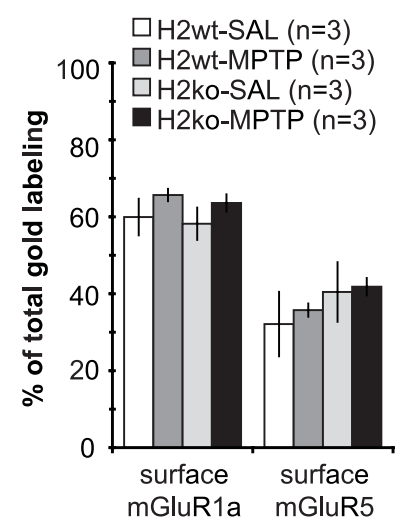

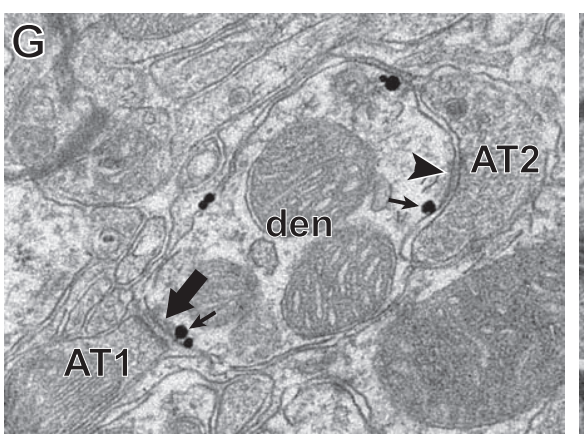

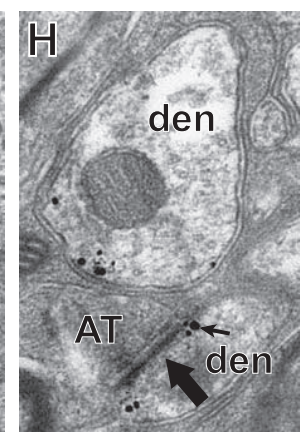

Figure 6. Preembedding immunogold labeling for mGluR1a and mGluR5 in GP and STN of wild-type and Homer-deficient mice treated with saline or MPTP. $A, B$, Relative proportion of the plasma membrane-bound gold labeling for mGluR1a and mGluR5 in GP dendrites of Homer $1(\boldsymbol{A})$ and Homer2 $(\boldsymbol{B})$ mice. Note that the proportion of plasma membrane-bound mGluR1a labeling is higher than that of mGluR5 labeling. Neither MPTP treatment nor H1 deletion significantly altered the plasma membrane expression of group I mGluRs. C, D, Electron micrographs of GP dendrites labeled for mGluR1a ( $($ ) or mGluR5 (D), contacted by axon terminals that establish asymmetric (large arrow) or symmetric (black arrowhead) synapses. Note the immunogold labeling at the edges of symmetric ( $\boldsymbol{D}$, small arrow) and asymmetric ( $\boldsymbol{C}$, small arrow) synapses, as well as within the main body of symmetric synapses ( $\boldsymbol{C}$, white arrowhead). $\boldsymbol{E}, \boldsymbol{F}$, Relative proportion of the plasma membrane-bound gold labeling for mGluR1a and mGluR5 in STN dendrites of Homer1 $(\boldsymbol{E})$ and Homer2 $(\boldsymbol{F})$ mice. Note that the proportion of the plasma membrane-bound mGluR1a labeling is higher than that of mGluR5 labeling. Neither MPTP treatment nor $\mathrm{H} 1$ deletion significantly altered the plasma membrane expression of group I mGluRs. $\mathbf{G}, \boldsymbol{H}$, Electron micrographs of STN dendrites labeled for mGluR1a (G) or mGluR5 $(\boldsymbol{H})$, contacted by terminal boutons that establish asymmetric (large arrow) or symmetric (black arrowhead) synapses. Note that immunogold labeling is found at the edges of symmetric ( $\boldsymbol{G}$, small arrow) and asymmetric $(\boldsymbol{G}, \boldsymbol{H}$, small arrows) synapses. Data presented here and in Figure 7 were compiled from 5039 gold particles in 819 GP dendrites from 24 animals for mGluR1a, 5865 gold particles in 797 GP dendrites from 24 animals for mGluR5, 4419 particles in 905 STN dendrites from 24 animals for mGluR1a, and 5682 particles in 826 STN dendrites from 24 animals for mGluR5. AT, Axon terminals; den, dendrites. Scale bar: $\mathbf{C}($ for $\boldsymbol{C}, \boldsymbol{D}, \mathbf{G}, \boldsymbol{H}), 0.5 \mu \mathrm{m}$.

\section{MPTP treatment and Homer deletion elicit complex changes in} $m$ GluR5 localization in GP and STN

In the GP, H2 deletion significantly increased the RD of synaptic mGluR5 at symmetric synapses, which was reversed by MPTP treatment (Fig. $7 F$, syn-sym) ( $p<0.05$ between H2wtSAL and H2ko-SAL; $p<0.01$ between H2ko-SAL and H2koMPTP; Tukey test). In the STN of H1wt animals, MPTP treatment significantly increased RD for perisynaptic mGluR5 at symmetric synapses, which was attenuated in MPTP-treated H1ko animals (Fig. $7 G$, peri-sym) ( $p<0.01$ between H1wtSAL and H1wt-MPTP; $p<0.05$ between H1wt-MPTP and H1ko-MPTP; Tukey test). MPTP treatment also significantly increased RD of extrasynaptic mGluR5 in the GP of H2wt animals (Fig. 7F, extrasyn) ( $p<0.05$ between H2wt-SAL and H2wt-MPTP; Tukey test), whereas there was a strong trend for MPTP-induced decrease in RD for perisynaptic mGluR5 at asymmetric synapses in the GP of H1ko (Fig. 7E, peri-asym) ( $p=0.058$ between H1ko-SAL and H1ko-MPTP; Tukey test) but not H1wt animals.

\section{Discussion}

The present in vivo study demonstrates that nigrostriatal dopaminergic lesion and Homer deletion induce changes in the expression and trafficking of mGluRla and mGluR5 in the mouse basal ganglia. The main findings are as follows: (1) MPTP treatment decreases the amount of H1a and mGluRla in the STR, (2) MPTP treatment increases presynaptic expression of mGluRla in GP and STN of normal mice, (3) the relative density of mGluR1a within the postsynaptic specialization of symmetric synapses is increased in the GP and STN of MPTP-treated H1 mice, (4) the subsynaptic localization of mGluR5 exhibits complex changes in response to MPTP treatment or Homer deletion, and (5) the glial expression of group I mGluRs in GP is altered in MPTP-treated and Homer knockout mice. Together, these findings provide evidence for complex, in vivo, regulatory changes of the localization and trafficking of group I mGluRs by dopamine and Homer in basal ganglia. 


\section{Reduced H1a and mGluR1a protein levels in parkinsonian STR}

Our data show that the total tissue expression levels of $\mathrm{Hla}$ and mGluRla were significantly reduced in the STR of MPTPtreated wild-type mice. Because H1a expression can be induced by cocaine (Brakeman et al., 1997), which increases extracellular dopamine concentration, this reduction of basal striatal Hla level could be attributed to a reduced dopamine content caused by MPTP-induced degeneration of the nigrostriatal pathway. Unlike STR, pallidal H1a level remained unchanged after the same treatment. This differential effect of dopamine depletion between STR and GP can be explained by the limited extent of the nigropallidal projection compared with the massive nigrostriatal system (Smith and Kieval, 2000). The reduced mGluR1a level in STR may be the result of MPTP-induced degeneration of presynaptic mGluRla in $\mathrm{TH}$ immunoreactive terminals (Paquet and Smith, 2003). However, we cannot rule out the possibility that the postsynaptic expression of mGluRla was downregulated by dopamine depletion.

\section{Increased axonal mGluR1a localization in parkinsonian GP and STN}

The present data demonstrate that MPTP treatment significantly increased axonal expression of mGluR1a in GP and STN of $\mathrm{H} 2$ wt. A small but statistically significant increase in terminal expression of mGluRla was also observed in GP of H1wt and H2wt. Thus, it appears that MPTP treatment promotes presynaptic expression of mGluR1a in these nuclei in wild-type animals. The exact source of these mGluR1a-labeled presynaptic elements remains to be established. Various sources should be considered, because the GP receives glutamatergic inputs from the STN and GABAergic afferents from the STR and local GP collaterals, whereas the STN receives GABAergic inputs from GP and glutamatergic inputs from the cortex, parafascicular thalamic nucleus, pedunculopontine nucleus, and local STN collaterals (Smith et al., 1998). Based on previous data indicating that Hla upregulation causes translocation of group I mGluRs into axonal processes (Ango et al., 2000), together with our observation demonstrating the downregulation of H1a in parkinsonian STR, it seems unlikely that the striatopallidal pathway is the main source of this postMPTP increase in mGluRla-labeled presynaptic elements in the GP. Conclusive identification of the origin of these mGluRlacontaining axons would require the use of anterograde tracing combined with immunolabeling for mGluRla. Interestingly, mGluR1a- and mGluR5-ir was found as discrete patches along

G. STN - mGluR5 0.05 ; Tukey test).
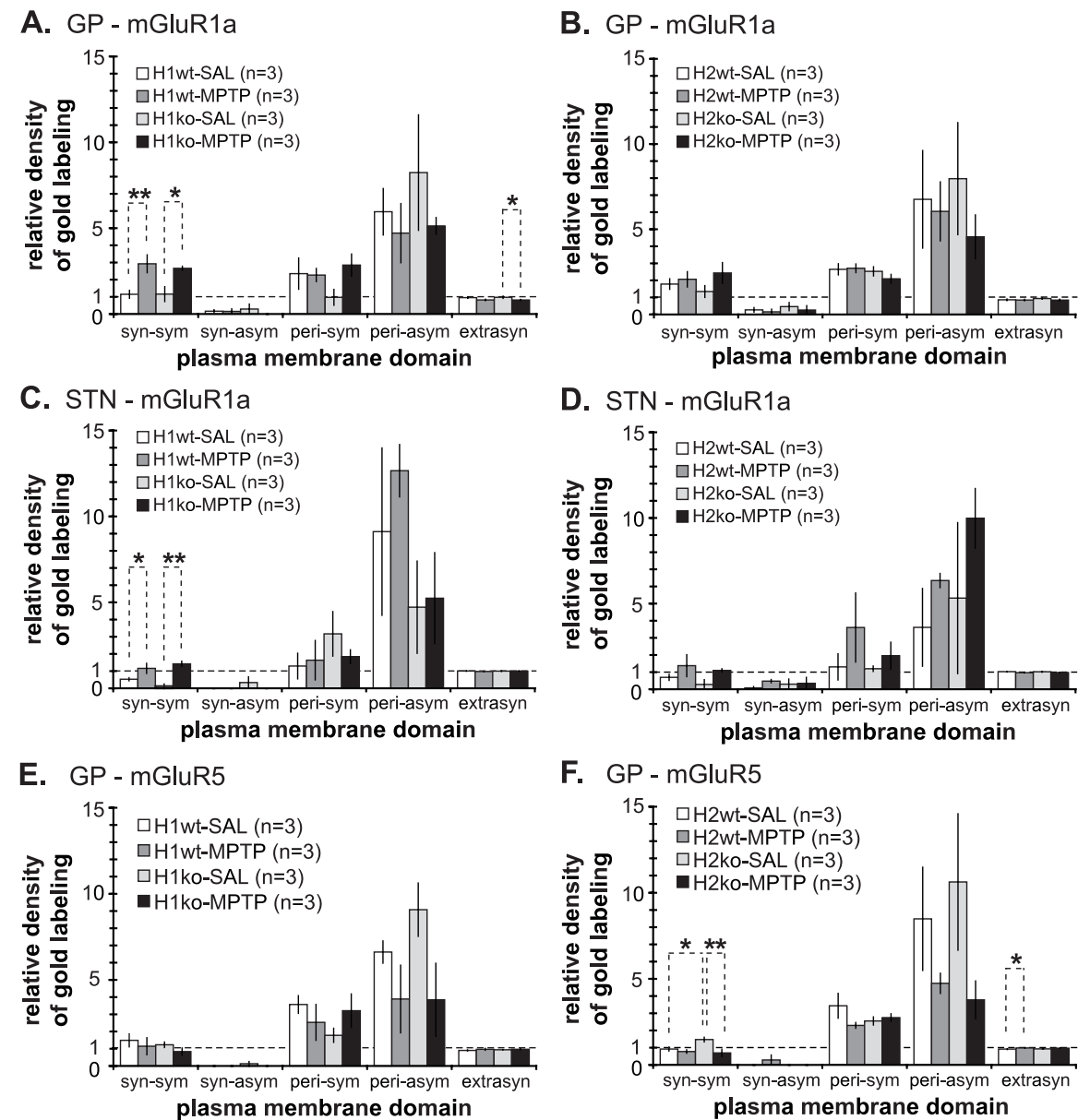

F. GP - mGluR5
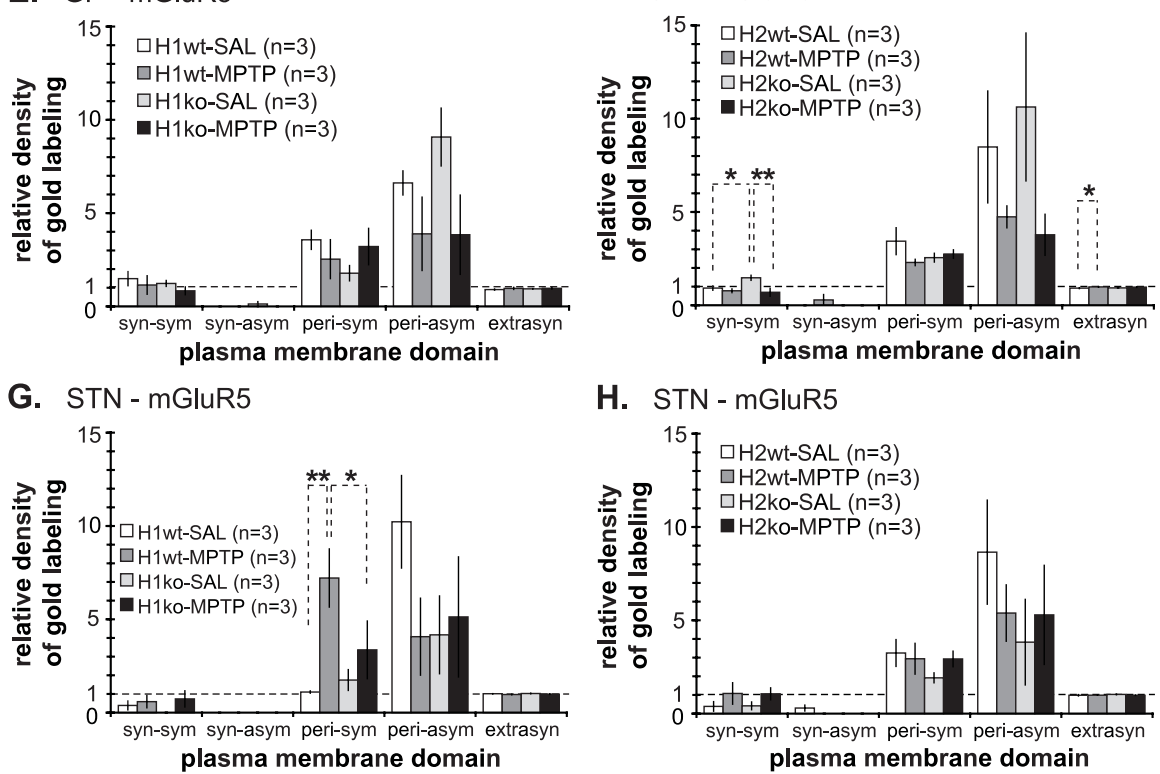

Figure 7. RD \pm SEM of immunogold labeling for mGluR1a $(\boldsymbol{A}-\boldsymbol{D})$ and mGluR5 $(\boldsymbol{E}-\boldsymbol{H})$ at different domain of the dendritic plasma membrane in $\mathrm{GP}(\boldsymbol{A}, \boldsymbol{B}, \boldsymbol{E}, \boldsymbol{F})$ and $\operatorname{STN}(\boldsymbol{C}, \boldsymbol{D}, \boldsymbol{G}, \boldsymbol{H})$. Values were calculated as the percentage of labeling for each receptor subtype at a given membrane domain divided by the percentage of the dendritic plasma membrane that contributes to that domain. Note that, in all cases, group I mGluRs are highly concentrated at the edges of asymmetric synapses (peri-asym) and, to a lesser extent, symmetric synapses (peri-sym). $\boldsymbol{A}, \boldsymbol{C}$, MPTP treatment significantly increased the RD of mGluR1a at symmetric synapses in GP $(\boldsymbol{A})$ and STN $(\boldsymbol{C})$ of H1wt and H1 ko mice $\left(\boldsymbol{A}, \boldsymbol{C}\right.$, syn-sym; ${ }^{*} p<0.05 ;{ }^{* *} p<0.01$; Tukey test), whereas extrasynaptic mGluR1a was significantly reduced in the GP of H1ko mice $\left(\boldsymbol{A}\right.$, extrasyn; ${ }^{*} p<0.05$; Tukey test). $\boldsymbol{F}$, $\mathrm{H} 2$ deletion significantly increased the density of synaptic mGluR5 at symmetric synapses ( $\boldsymbol{F}$, syn-sym; ${ }^{*} p<0.05$; Tukey test), which was reversed by MPTP treatment of H2ko mice $\left(\boldsymbol{F}\right.$, syn-sym; ${ }^{* *} p<0.01$; Tukey test). The RD of extrasynaptic mGluR5 was also significantly increased by MPTP treatment in $\mathrm{H} 2 \mathrm{wt}\left(\boldsymbol{F}\right.$, extrasyn; ${ }^{*} p<0.05$; Tukey test). $\boldsymbol{G}$, The RD of perisynaptic mGluR5 was significantly increased by MPTP treatment in H1wt (G, peri-sym; ${ }^{* *} p<0.01$; Tukey test), which was reversed in MPTP-treated H1ko (G, peri-sym; ${ }^{*} p<$

the length of unmyelinated axons. This pattern of axonal labeling resembles that of pallidal mGluR2/3, which mediate presynaptic inhibition of excitatory neurotransmission in rat GP (Poisik et al., 2005). Assuming that the axonally expressed group I mGluRs are functional, one could hypothesize that activation of these receptors might lead to presynaptic regulation of neurotransmitter release. Indeed, activation of group I mGluRs in the rat STN causes presynaptic inhibition of exci- 
tatory neurotransmission (Awad-Granko and Conn, 2001), but such effect has not been described in the GP.

An overall reduction of mGluR1a, but not mGluR5, immunoreactivity has recently been reported in the external and internal pallidum of MPTP-treated monkeys (Kaneka et al., 2005). In contrast, we did not find any obvious change in the level of mGluRla immunoreactivity in the mouse GP. Future studies are needed to assess whether these observations represent genuine species differences between primates and nonprimates in response to dopamine depletion or the result of technical differences between the two studies.

\section{Regulation of postsynaptic group I mGluRs localization by dopamine and Homer}

Our findings indicate that MPTP treatment increases the density of mGluRla at symmetric, putative GABAergic, synapses in the mouse GP and STN independent of H1. The presence of group I mGluRs at GABAergic synapses has been described previously in the basal ganglia (Hanson and Smith, 1999; Hubert et al., 2001; Paquet and Smith, 2003; Kuwajima et al., 2004), although the functional significance of this receptor localization remains unknown. Activation of group I mGluRs may modulate GABAergic neurotransmission at these synapses. For instance, activation of mGluR5 enhances $\mathrm{GABA}_{\mathrm{A}}$-mediated currents in a $\mathrm{Ca}^{2+}$ - and PKC-dependent manner in retinal amacrine cells (Hoffpauir and Gleason, 2002). Activation of $\mathrm{GABA}_{\mathrm{B}}$ receptors can also enhance mGluR1-mediated EPSCs in cerebellar Purkinje neurons (Hirono et al., 2001; Tabata et al., 2004), from which these receptors coimmunoprecipitate (Tabata et al., 2004). Although not demonstrated in the basal ganglia, such functional interactions between group I mGluRs and GABA receptors could potentially influence neuronal activity of GP and STN neurons.

MPTP treatment and Homer deletion elicited complex effects on mGluR5 localization in GP and STN neurons. In GP, MPTP treatment decreased the RD of perisynaptic mGluR5 at asymmetric synapses in H1ko, whereas extrasynaptic mGluR5 in $\mathrm{H} 2 \mathrm{wt}$ was increased. $\mathrm{H} 2$ deletion significantly increased the RD of synaptic mGluR5 at symmetric synapses in GP, which was reversed in MPTP-treated H2ko. In the STN of H1wt mice, the RD of perisynaptic mGluR5 at symmetric synapses was increased by MPTP treatment, which was attenuated in MPTP-treated H1ko mice. Although the functional significance of these changes remains to be established, the fact that the effects of MPTP treatment and Homer deletion affected differently the two group I mGluR subtypes suggests a certain degree of specificity of the regulatory mechanisms of the trafficking and subsynaptic targeting of mGluR1a and mGluR5 in the basal ganglia.

It is noteworthy that neither MPTP treatment nor Homer deletion significantly affected the proportion of group I mGluRs expressed on the surface of dendritic plasma membrane in GP and STN. In normal rat STN neurons, slow depolarization induced by the group I mGluR agonist 3,4-dihydroxyphenylglycol (DHPG) is solely mediated by mGluR5 (Awad et al., 2000). However, both mGluR1 and mGluR5 mediate DHPG-induced depolarization after treatment with haloperidol, which causes acute parkinsonian-like catalepsy (Marino et al., 2002). Based on the present observation that dopamine depletion does not affect the plasma membrane localization of group I mGluRs, these alterations in receptor signaling may be caused by other regulatory mechanisms, such as an altered phosphorylation state of group I mGluRs and other signaling molecules.

The glial localization of group I mGluRs in GP was also altered by MPTP treatment and/or Homer deletion. MPTP treatment significantly increased the density of mGluR1a-labeled glial processes in H2wt. Also, the glial expression of mGluR5 in GP was significantly decreased by $\mathrm{H} 1$ deletion, which was reversed in MPTP-treated H1ko mice. Although very little is known about the roles of Homer proteins in glial cells, their expression has been demonstrated in Mueller radial glia of the Xenopus retina (Foa et al., 2005) and cultured rat hypothalamic astrocytes, from which Homers coimmunoprecipitate with mGluR5 (Dziedzic et al., 2003). Thus, our findings provide additional evidence that Homer proteins affect the expression of group I mGluRs in glial cells.

\section{mGluR5 antagonists and Parkinson's disease}

Application of the mGluR5 selective antagonist 2-methyl-6(phenylethynyl)pyridine (MPEP) enhances mGluRla-mediated depolarization in the GP (Poisik et al., 2003) and inhibits DHPGinduced depolarization in the STN (Awad et al., 2000). Because such effects of MPEP may enhance the activity of GP neurons and thereby produce inhibition of the STN in parkinsonism, mGluR5 is considered as a novel target for Parkinson's disease pharmacotherapy (Marino et al., 2003; Conn et al., 2005). Recent studies indicate that chronic MPEP treatment attenuates akinetic motor deficits and increases the neuronal metabolic activity in STN caused by partial bilateral 6-hydroxydopamine lesions in rats (Breysse et al., 2002, 2003). This suggests that MPEP may have beneficial effects in treating early stages of Parkinson's disease. Because the dendritic surface expression of mGluR5 remains unaffected in mouse GP and STN after severe MPTP-induced dopamine depletion, our findings suggest that the target sites of MPEP in key basal ganglia nuclei remain available for pharmacotherapy, even in late-stage parkinsonism.

Together with previous observations on the altered expression of AMPA and NMDA receptors in parkinsonism (Wullner et al., 1993, 1994; Porter et al., 1994; Lange et al., 1997; Betarbet et al., 2000), these findings support the notion that glutamatergic neurotransmission undergoes changes in the parkinsonian basal ganglia and that drugs acting at glutamate receptors could be beneficial in treating parkinsonism (Blandini et al., 2000; Marino et al., 2003). Our findings also suggest that the roles of HomermGluR interactions on group I mGluRs trafficking in vivo are likely specific to the receptor subtypes, brain areas, and cell types.

\section{References}

Ango F, Pin JP, Tu JC, Xiao B, Worley PF, Bockaert J, Fagni L (2000) Dendritic and axonal targeting of type 5 metabotropic glutamate receptor is regulated by homerl proteins and neuronal excitation. J Neurosci 20:8710-8716.

Awad H, Hubert GW, Smith Y, Levey AI, Conn PJ (2000) Activation of metabotropic glutamate receptor 5 has direct excitatory effects and potentiates NMDA receptor currents in neurons of the subthalamic nucleus. J Neurosci 20:7871-7879.

Awad-Granko H, Conn PJ (2001) Activation of groups I or III metabotropic glutamate receptors inhibits excitatory transmission in the rat subthalamic nucleus. Neuropharmacology 41:32-41.

Betarbet R, Porter RH, Greenamyre JT (2000) GluR1 glutamate receptor subunit is regulated differentially in the primate basal ganglia following nigrostriatal dopamine denervation. J Neurochem 74:1166-1174.

Bezard E, Dovero S, Bioulac B, Gross C (1997) Effects of different schedules of MPTP administration on dopaminergic neurodegeneration in mice. Exp Neurol 148:288-292.

Blackstad TW, Karagulle T, Ottersen OP (1990) MORFOREL, a computer program for two-dimensional analysis of micrographs of biological specimens, with emphasis on immunogold preparations. Comput Biol Med 20:15-34.

Blandini F, Nappi G, Tassorelli C, Martignoni E (2000) Functional changes 
of the basal ganglia circuitry in Parkinson's disease. Prog Neurobiol 62:63-88.

Brakeman PR, Lanahan AA, O’Brien R, Roche K, Barnes CA, Huganir RL, Worley PF (1997) Homer: a protein that selectively binds metabotropic glutamate receptors. Nature 386:284-288.

Breysse N, Baunez C, Spooren W, Gasparini F, Amalric M (2002) Chronic but not acute treatment with a metabotropic glutamate 5 receptor antagonist reverses the akinetic deficits in a rat model of parkinsonism. J Neurosci 22:5669-5678.

Breysse N, Amalric M, Salin P (2003) Metabotropic glutamate 5 receptor blockade alleviates akinesia by normalizing activity of selective basalganglia structures in parkinsonian rats. J Neurosci 23:8302-8309.

Conn PJ, Battaglia G, Marino MJ, Nicoletti F (2005) Metabotropic glutamate receptors in the basal ganglia motor circuit. Nat Rev Neurosci 6:787-798.

de Bartolomeis A, Iasevoli F (2003) The homer family and the signal transduction system at glutamatergic postsynaptic density: potential role in behavior and pharmacotherapy. Psychopharmacol Bull 37:51-83.

Dziedzic B, Prevot V, Lomniczi A, Jung H, Cornea A, Ojeda SR (2003) Neuron-to-glia signaling mediated by excitatory amino acid receptors regulates ErbB receptor function in astroglial cells of the neuroendocrine brain. J Neurosci 23:915-926.

Ferraguti F, Conquet F, Corti C, Grandes P, Kuhn R, Knopfel T (1998) Immunohistochemical localization of the mGluRlbeta metabotropic glutamate receptor in the adult rodent forebrain: evidence for a differential distribution of mGluR1 splice variants. J Comp Neurol 400:391-407.

Foa L, Jensen K, Rajan I, Bronson K, Gasperini R, Worley PF, Tu JC, Cline HT (2005) Homer expression in the Xenopus tadpole nervous system. J Comp Neurol 487:42-53.

Hanson JE, Smith Y (1999) Group I metabotropic glutamate receptors at GABAergic synapses in monkeys. J Neurosci 19:6488-6496.

Hanson JE, Smith Y (2002) Subcellular distribution of high-voltageactivated calcium channel subtypes in rat globus pallidus neurons. J Comp Neurol 442:89-98.

Hanson JE, Smith Y, Jaeger D (2004) Sodium channels and dendritic spike initiation at excitatory synapses in globus pallidus neurons. J Neurosci 24:329-340.

Hirono M, Yoshioka T, Konishi S (2001) GABA(B) receptor activation enhances mGluR-mediated responses at cerebellar excitatory synapses. Nat Neurosci 4:1207-1216.

Hoffpauir BK, Gleason EL (2002) Activation of mGluR5 modulates GABA(A) receptor function in retinal amacrine cells. J Neurophysiol 88:1766-1776.

Hubert GW, Paquet M, Smith Y (2001) Differential subcellular localization of mGluR1a and mGluR5 in the rat and monkey substantia nigra. J Neurosci 21:1838-1847.

Kaneka K, Tachibana Y, Imanishi M, Kita H, Shigemoto R, Nambu A, Takada M (2005) Down-regulation of metabotropic glutamate receptor lalpha in globus pallidus and substantia nigra of parkinsonian monkeys. Eur J Neurosci 22:3241-3254.

Kuwajima M, Hall RA, Aiba A, Smith Y (2004) Subcellular and subsynaptic localization of group I metabotropic glutamate receptors in the monkey subthalamic nucleus. J Comp Neurol 474:589-602.

Kuwajima M, Hall RA, Smith Y (2005) Expression of group I metabotropic glutamate receptors in the pallido-subthalamic complex in the MPTPmouse model of Parkinson's disease. Soc Neurosci Abstr 31:331.18.

Lange KW, Kornhuber J, Riederer P (1997) Dopamine/glutamate interactions in Parkinson's disease. Neurosci Biobehav Rev 21:393-400.

Marino M, Valenti O, Conn PJ (2003) Glutamate receptors and Parkinson's disease: opportunities for intervention. Drugs Aging 20:377-397.

Marino MJ, Wittmann M, Bradley SR, Hubert GW, Smith Y, Conn PJ (2001) Activation of group I metabotropic glutamate receptors produces a direct excitation and disinhibition of GABAergic projection neurons in the substantia nigra pars reticulata. J Neurosci 21:7001-7012.

Marino MJ, Awad-Granko H, Ciombor KJ, Conn PJ (2002) Haloperidolinduced alteration in the physiological actions of group I mGlus in the subthalamic nucleus and the substantia nigra pars reticulata. Neuropharmacology 43:147-159.

Matsumoto Y (1985) Simultaneous inhibition of endogenous avidinbinding activity and peroxidase applicable for the avidin-biotin system using monoclonal antibodies. Histochemistry 83:325-330.

McKay BE, Molineux ML, Turner RW (2004) Biotin is endogenously expressed in select regions of the rat central nervous system. J Comp Neurol 473:86-96.
Miller GW, Staley JK, Heilman CJ, Perez JT, Mash DC, Rye DB, Levey AI (1997) Immunochemical analysis of dopamine transporter protein in Parkinson's disease. Ann Neurol 41:530-539.

Paquet M, Smith Y (2003) Group I metabotropic glutamate receptors in the monkey striatum: subsynaptic association with glutamatergic and dopaminergic afferents. J Neurosci 23:7659-7669.

Paxinos G, Franklin KBJ (2001) The mouse brain in stereotaxic coordinates, Ed 2. San Diego: Academic.

Poisik O, Raju DV, Verreault M, Rodriguez A, Abeniyi OA, Conn PJ, Smith Y (2005) Metabotropic glutamate receptor 2 modulates excitatory synaptic transmission in the rat globus pallidus. Neuropharmacology 49 [Suppl 1]:57-69.

Poisik OV, Mannaioni G, Traynelis S, Smith Y, Conn PJ (2003) Distinct functional roles of the metabotropic glutamate receptors 1 and 5 in the rat globus pallidus. J Neurosci 23:122-130.

Porter RH, Greene JG, Higgins Jr DS, Greenamyre JT (1994) Polysynaptic regulation of glutamate receptors and mitochondrial enzyme activities in the basal ganglia of rats with unilateral dopamine depletion. J Neurosci 14:7192-7199.

Roche KW, Tu JC, Petralia RS, Xiao B, Wenthold RJ, Worley PF (1999) Homer $1 \mathrm{~b}$ regulates the trafficking of group I metabotropic glutamate receptors. J Biol Chem 274:25953-25957.

Shin DM, Dehoff M, Luo X, Kang SH, Tu J, Nayak SK, Ross EM, Worley PF, Muallem S (2003) Homer 2 tunes G protein-coupled receptors stimulus intensity by regulating RGS proteins and PLCbeta GAP activities. J Cell Biol 162:293-303.

Shiraishi Y, Mizutani A, Mikoshiba K, Furuichi T (2003) Coincidence in dendritic clustering and synaptic targeting of homer proteins and NMDA receptor complex proteins NR2B and PSD95 during development of cultured hippocampal neurons. Mol Cell Neurosci 22:188-201.

Shiraishi Y, Mizutani A, Yuasa S, Mikoshiba K, Furuichi T (2004) Differential expression of Homer family proteins in the developing mouse brain. J Comp Neurol 473:582-599.

Smith Y, Kieval JZ (2000) Anatomy of the dopamine system in the basal ganglia. Trends Neurosci 23:S28-S33.

Smith Y, Bevan MD, Shink E, Bolam JP (1998) Microcircuitry of the direct and indirect pathways of the basal ganglia. Neuroscience 86:353-387.

Sun J, Tadokoro S, Imanaka T, Murakami SD, Nakamura M, Kashiwada K, Ko J, Nishida W, Sobue K (1998) Isolation of PSD-Zip45, a novel Homer/vesl family protein containing leucine zipper motifs, from rat brain. FEBS Lett 437:304-308.

Tabata T, Araishi K, Hashimoto K, Hashimotodani Y, van der Putten H, Bettler B, Kano M (2004) Ca2+ activity at GABAB receptors constitutively promotes metabotropic glutamate signaling in the absence of GABA. Proc Natl Acad Sci USA 101:16952-16957.

Testa CM, Friberg IK, Weiss SW, Standaert DG (1998) Immunohistochemical localization of metabotropic glutamate receptors mGluRla and mGluR2/3 in the rat basal ganglia. J Comp Neurol 390:5-19.

Valenti O, Conn PJ, Marino MJ (2002) Distinct physiological roles of the Gq-coupled metabotropic glutamate receptors co-expressed in the same neuronal populations. J Cell Physiol 191:125-137.

Veznedaroglu E, Milner TA (1992) Elimination of artifactual labeling of hippocampal mossy fibers seen following pre-embedding immunogold-silver technique by pretreatment with zinc chelator. Microsc Res Tech 23:100-101.

Wichmann T, DeLong MR (2003) Pathophysiology of Parkinson's disease: the MPTP primate model of the human disorder. Ann NY Acad Sci 991:199-213.

Wullner U, Brouillet E, Isacson O, Young AB, Penney JB (1993) Glutamate receptor binding sites in MPTP-treated mice. Exp Neurol 121:284-287.

Wullner U, Testa CM, Catania MV, Young AB, Penney Jr JB (1994) Glutamate receptors in striatum and substantia nigra: effects of medial forebrain bundle lesions. Brain Res 645:98-102.

Xiao B, Tu JC, Worley PF (2000) Homer: a link between neural activity and glutamate receptor function. Curr Opin Neurobiol 10:370-374.

Xiao B, Tu JC, Petralia RS, Yuan JP, Doan A, Breder CD, Ruggiero A, Lanahan AA, Wenthold RJ, Worley PF (1998) Homer regulates the association of group 1 metabotropic glutamate receptors with multivalent complexes of homer-related, synaptic proteins. Neuron 21:707-716.

Yuan JP, Kiselyov K, Shin DM, Chen J, Shcheynikov N, Kang SH, Dehoff MH, Schwarz MK, Seeburg PH, Muallem S, Worley PF (2003) Homer binds TRPC family channels and is required for gating of TRPC1 by IP3 receptors. Cell 114:777-789. 